\title{
Mobilidade populacional e as novas espacialidades urbanas: municípios da Ompetro, Rio de Janeiro (2000-2010)
}

Joseane de Souza. Universidade Estadual do Norte Fluminense (UEnf) - Darcy Ribeiro, Río de Janeiro, Brasil.

Denise Terra. Universidade Estadual do Norte Fluminense (Uenf) - Darcy Ribeiro, Río de Janeiro, Brasil.

Mauro Campos. Universidade Estadual do Norte Fluminense (UEnf) - Darcy Ribeiro, Río de Janeiro, Brasil.

Resumo | A Organização dos Municípios Produtores de Petróleo e Gás Natural e Limítrofes da Zona de Produçáo Principal da Bacia de Campos (Ompetro), fundada em 2001, inclui nove municípios litorâneos do Estado do Rio de Janeiro. O desenvolvimento da atividade produtiva -reestruturaçáo, sofisticação e diversificação da produção, dos serviços e do consumo- decorrentes do desenvolvimento da atividade petrolífera, a partir de meados dos anos 70, vem provocando uma série de transformaçóes na região. Nesse sentido, esse artigo tem como objetivo analisar o processo de formação dessa nova espacialidade urbana, enfatizando a mobilidade da população entre estes municípios no período 2000 e 2010. Para tanto, foi mensurada a magnitude dos fluxos pendulares, estimados os principais indicadores de seus impactos sobre as respectivas populaçóes de origem, e analisadas as características socioeconômicas e demográficas dos trabalhadores que realizam esse movimento quotidianamente.

PALAVRAS-CHAVES | demografia, mercado de trabalho, transformaçôes socioterritoriais.

abstract | The Petroleum and Natural Gas Exporting Counties Bordering the Main Production Zone of the Campos Basin Organization (Ompetro), founded in 2001, includes nine coastal municipalities of the State of Rio de Janeiro. The development of productive activity -restructuring, increased sophistication and diversification of production and consumption of services- based on the development of the oil industry starting in the mid-1970s, has led to a series of transformations in the region. This article aims to analyze the process of the formation of a new urban spatiality, emphasizing population mobility between these municipalities between 2000 and 2010. To achieve this, the magnitude of commuter mobility was measured, estimating the leading indicators of the impact of such mobility on the populations of origin, and analyzing the socioeconomic and demographic characteristics of the workers who commute in this manner on a daily basis.

KEY WORDS | demography, labour market, socio-territorial transformations.

Recibido el 11 de marzo de 2013, aprobado el 27 de octubre de 2013

E-mail: J. de Souza, fernandes.souza.joseane@gmail.com | D. Terra, deniseterra@gmail.com | M. Campos, mauromcampos@yahoo.com.br Correspondencia: Universidade Estadual do Norte Fluminense, Centro de Ciências do Homem, Laboratório de Gestáo e Políticas Públicas, Avenida Alberto Lamego, 2000, Parque Califórnia, Campos dos Goytacazes, Rio de Janeiro, Brasil 


\section{Introduçáo}

A ocupação do Norte Fluminense (NF) -região que atualmente corresponde aos municípios de Campos dos Goytacazes, São João da Barra, Macaé, São Fidélis, Conceição de Macabu, Quissamã, Cardoso Moreira, Carapebus e São Francisco do Itabapoana- se iniciou na primeira metade do século XvII e, de meados do século XVIII até praticamente meados dos anos 1970, esteve relacionada à produção de cana-de-açúcar.

No entanto, desde os anos 60 até o momento atual, a década de 70 foi o único período em que o setor sucroalcooleiro experimentou uma fase de prosperidade, como reflexo da escassez do açúcar, no mercado internacional, em que pesem as iniciativas do Instituto do Açúcar e do Álcool (IAA) para manter elevado o preço do açúcar, e a criação do Programa Brasileiro de Álcool (Proálcool). No final dos anos 70 e início dos anos 80 , o setor experimentou uma nova fase de arrefecimento, da qual não mais se recuperou.

Paralelamente à decadência da indústria sucroalcooleira, observa-se a implantação da Petrobras em Macaé, em 1974, e o início da exploração do petróleo na Bacia de Campos -bacia sedimentar situada na costa norte do estado do Rio de Janeiro, estendendo-se até o sul do Espírito Santo-. Indubitavelmente, este fator contribuiu significativamente para amenizar o cenário da crise.

Acontece, porém, que os impactos da atividade petrolífera não se deram exatamente sobre os municípios do norte fluminense. Nessa regiáo, apenas os municípios litorâneos e produtores de petróleo -Sáo João da Barra, Campos dos Goytacazes, Quissamã, Carapebus e Macaé- sofreram impactos significativos. Outros municípios produtores de petróleo na Bacia da Campos, mas náo pertencentes ao Norte Fluminense -Rio das Ostras, Casimiro de Abreu, Armaçáo de Búzios e Cabo Frio, na Baixada Litorânea- também sofreram os impactos da atividade petrolífera e, assim como os municípios do Norte Fluminense antes mencionados, também são beneficiários das compensaçóes financeiras.

A partir de 2001, esses municípios passaram a constituir a Ompetro -Organização dos Municípios Produtores de Petróleo, e Gás e Limítrofes da Zona de Produçáo Principal da Bacia de Campos-. Atualmente, além desses, fazem parte da Ompetro os municípios de Niterói e Arraial do Cabo.

Dentre as mudanças que a atividade petrolífera tem gerado nos municípios da Ompetro, destaca-se a da dinâmica demográfica regional, com a aceleração do ritmo de crescimento populacional, devido aos movimentos migratórios rurais-urbanos, intraestaduais, interestaduais e, inclusive, internacionais. Em muitas aglomeraçóes urbanas brasileiras, paralelamente à aceleração do crescimento, verificou-se um aumento significativo dos movimentos pendulares. Em parte, são associados à própria redistribuição espacial da população, proporcionada pelas migraçóes internas; outra causa, devido à redistribuição espacial da atividade econômica. Nas antigas e também nas novas aglomeraçóes urbanas, o local de trabalho vem se dissociando do local de residência, não apenas para os migrantes -como os migrantes intrametropolitanos, no caso das RMs- mas igualmente para os não migrantes. 
Nos municípios da Ompetro, o desenvolvimento da atividade produtiva -reestruturação, sofisticação e diversificação da produção, dos serviços e do consumovem mudando o centro de gravidade econômica. Assim, Campos dos Goytacazes, embora permaneça como polo regional, vem perdendo importância relativa, principalmente para Macaé, considerada a Capital do Petróleo. Nesse contexto, é muito provável que, além do recrudescimento dos movimentos migratórios, já verificado por Fernandes, Terra e Campos (2012), tenha havido um aumento dos movimentos pendulares em direção aos municípios da Ompetro.

Desse modo, o presente artigo tem como objetivo identificar os fluxos pendulares entre os municípios da Ompetro, no período 2000 e 2010, analisar sua magnitude, estimar os saldos pendulares, e identificar as principais origens e destinos desses trabalhadores. No intuito de contribuir para uma melhor compreensão dos processos de seletividade e de especialização do espaço regional, serão analisados alguns indicadores socioeconômicos e demográficos dos principais fluxos pendulares.

$\mathrm{O}$ artigo está dividido, incluindo a introdução, em sete seçôes. Na segunda seção serão apresentadas algumas consideraçóes teóricas sobre a mobilidade espacial da população; na terceira, serão abordadas as principais características do processo de urbanização brasileiro. $\mathrm{Na}$ seção seguinte, apresenta-se breve análise sobre o processo de formação e expansão urbana da Ompetro. Na quinta seção, são apresentadas as fontes de dados e a metodologia utilizada para análise das informaçóes sobre a mobilidade pendular e, complementando, na sexta seção, a análise das mesmas.

\section{Consideraçóes teóricas sobre a mobilidade espacial da populaçáo}

"As Leis da Migração" é a primeira teoria que trata dos movimentos migratórios, e foi elaborada por Ravenstein (1980 [1885]) ao analisar mudanças de residência entre condados do Reino Unido, utilizando informaçóes dos Censos de 1871 e 1881. Dentre as leis de migração de Ravenstein (1980 [1885]), destacam-se: a relação direta entre desenvolvimento tecnológico, principalmente nos setores de transporte e comunicação, a intensidade do movimento migratório e o predomínio do motivo econômico.

Apesar das várias críticas recebidas, principalmente em relação à pretensão de criar leis gerais de migração a partir do caso específico do Reino Unido, essa teoria é considerada "clássica", tendo fundamentado várias outras, que buscam analisar a intensidade, as características, a natureza e os determinantes da migração. Algumas delas buscam explicar os movimentos migratórios a partir do indivíduo, da família ou do domicilio (aspectos micros), enquanto outras buscam explicá-los a partir dos fatores econômicos, sociais, demográficos etc., associados às regióes de origem e destino (aspectos macros). Dentre os que abordam os aspectos micros, destacam-se as teorias de Sjaastad (1980 [1962]), Todaro (1980 [1969]), e Mincer (1978). Por outro lado, Lee (1980 [1966]), Germani (1974), Singer (1980[1976]) são alguns que abordam os aspectos macros.

Independentemente de partirem de aspectos micros ou macros, essas teorias sugerem que as migraçóes são necessárias para o desenvolvimento do capitalismo e para a modernização da sociedade. Sugerem, ainda, que os movimentos migratórios 
implicam ascensão social, já que consideram as melhorias das condiçôes socioeconômicas dos migrantes após a mudança de residência.

Martine (1980) apresenta uma visão menos otimista sobre a relação entre mobilidade espacial e social. Analisando as migraçóes nas principais Regióes Metropolitanas brasileiras, utilizando o Censo de 1970, verificou que, apesar do grande poder de atração exercido pela metrópole sobre os migrantes, são poucos os que lá conseguem se estabelecer. Isso se deve aos acirrados mecanismos de seletividade populacional que ali atuam. Afirma ainda que, para a maioria dos indivíduos a (re) emigração -que normalmente se dá para outro município da própria Região Metropolitana- seria, antes, uma estratégia de sobrevivência e não uma possibilidade de ascensão social.

Segundo Matos (2000), no Brasil, o processo de concentração econômica e demográfica atingiu seu ponto máximo ao longo dos anos 70, quando teve início o processo de "reversão da polarização", como afirma Redwood (1984).

Segundo o autor, o processo de desconcentração populacional está estritamente relacionado à descentralização industrial e ao setor de serviços. É promovido, por um lado, pelas crescentes deseconomias de aglomeração, nas grandes metrópoles -que "normalmente acompañan a la expansión urbana en concentraciones de población que crecen rápidamente y a gran escala” (Redwood, 1984, p. 40) - e, por outro lado, pelas crescentes economias de escala e de aglomeração, incluindo as economias de localização e de urbanização, promovidas pelas metrópoles regionais e por algumas cidades de médio porte.

A "reversão da polarização" da atividade produtiva, na medida em que é acompanhada pela expansão dos postos de trabalho em áreas não metropolitanas, implica, necessariamente, na redistribuição espacial da população. Para Redwood (1984), os novos movimentos migratórios estariam refletindo "las crecientes ventajas comparativas de las ciudades "secundarias", las que incluyen áreas metropolitanas menores, tanto como centros urbanos de tamaño medio" (p. 41).

De fato, a partir dos anos 70 verifica-se, no Brasil, paralelamente aos processos de expansão urbana metropolitana e da periferização da população nas áreas metropolitanas, um processo de "desconcentração concentrada" da população, marcado pelo crescimento acelerado de novas espacialidades urbanas não metropolitanas.

Tendo em vista a tendência para a concentração da população em áreas urbanas metropolitanas, alguns pesquisadores como Cunha (1995), Brito e Souza (2005), Ântico (2005) e Aranha (2005), entre outros, analisaram os movimentos pendulares entre municípios metropolitanos. De fato, como ressaltam Moura, Castello Branco e Firkowski (2005), "nesse sistema de assentamento os deslocamentos para o trabalho assumem importância crescente, integrando o núcleo metropolitano, que é o centro da produção, às áreas do entorno residencial" (p. 122).

No entanto, com a "reversão da polarização" os movimentos pendulares vêm-se multiplicando, principalmente nas "novas espacialidades urbanas" onde o avanço tecnológico, sobretudo nos setores de transporte e comunicaçóes, tem provocado para um número cada vez maior de pessoas, a dissociação entre o local de residência e o local de trabalho. Essas áreas vêm reproduzindo, em menor medida, a forma urbana característica das aglomeraçôes metropolitanas, em geral constituídas 
"por um núcleo de atividades terceirizadas e por uma periferia residencial" (Moura, Castello Branco \& Firkowski, 2005, p. 122), e esses movimentos expressam não só a integração urbana, como ressaltam Pereira e Herrero (2009), mas também a assimetria entre municípios de determinada região.

\section{Da metropolização à interiorizaçáo do crescimento}

O processo de urbanização brasileiro, iniciado nos anos 30, pode ser percebido pelo aumento contínuo e ininterrupto da população residente em áreas urbanas, no período 1940-2010 (Quadro 1). Apenas a partir de 1970 -quando, pela primeira vez, a população residente em áreas urbanas superou a população rural-o Brasil se tornou um país urbano. Observa-se, no Quadro 2, que o grau de urbanização brasileiro, em 1970, refletia, na realidade, o intenso processo de urbanização da região sudeste, enquanto nas demais regióes a maior parcela da populaçáo continuava residindo em áreas rurais.

Chama a atenção a velocidade do processo: no período 1950-1960, enquanto a população brasileira crescia em torno de $3 \%$ ao ano, a população urbana crescia a um ritmo médio anual de 5,24\%. Ressalte-se que ritmo de crescimento tão alucinante quanto este foi também observado nos anos 1960-1970, momento em que a taxa de crescimento da população total brasileira já se apresentava em declínio. A partir dos anos 70 -quando a população rural apresentou, pela primeira vez, taxas negativas de crescimento, refletindo seu decréscimo absoluto- observa-se uma desaceleração no ritmo de crescimento da população urbana, embora esta permaneça como aquela que mais cresce no Brasil atual. Em apenas dez anos -de 1970 para 1980 - a população urbana superou a rural, em todas as regióes do país. Em 2010, mais de $84 \%$ da população brasileira residia em áreas urbanas.

QUAdro I | Brasil - População, segundo a situaçáo do domicílio; taxa de crescimento médio anual e grau de urbanização, 1940-2010

\begin{tabular}{|l|c|c|c|c|c|c|c|}
\hline \multirow{2}{*}{ ANO } & \multicolumn{3}{|c|}{ POPULAÇÃO } & \multicolumn{2}{c|}{ TAXA DE CRESCIMENTO } & \multirow{2}{*}{$\begin{array}{c}\text { GRAU DE } \\
\text { URBANIZAÇÁO }\end{array}$} \\
\cline { 2 - 7 } & URBANA & RURAL & TOTAL & URBANA & RURAL & TOTAL & \\
\hline 1940 & 12.880 .182 & 28.356 .133 & 41.236 .315 & & & & 31,24 \\
\hline 1950 & 18.782 .891 & 33.161 .506 & 51.944 .397 & 3,84 & 1,58 & 2,34 & 36,16 \\
\hline 1960 & 31.303 .034 & 38.767 .423 & 70.070 .457 & 5,24 & 1,57 & 3,04 & 44,67 \\
\hline 1970 & 52.084 .984 & 41.054 .053 & 93.139 .037 & 5,22 & 0,57 & 2,89 & 55,92 \\
\hline 1980 & 80.436 .409 & 38.566 .297 & 119.002 .706 & 4,44 & $-0,62$ & 2,48 & 67,59 \\
\hline 1991 & 110.990 .990 & 35.834 .485 & 146.825 .475 & 2,97 & $-0,67$ & 1,93 & 75,59 \\
\hline 2000 & 137.925 .238 & 31.947 .618 & 169.872 .856 & 2,49 & $-1,29$ & 1,66 & 81,19 \\
\hline 2010 & 160.925 .792 & 29.830 .007 & 190.755 .799 & 1,55 & $-0,68$ & 1,17 & 84,36 \\
\hline
\end{tabular}

Fonte instituto brasileiro de Geografia e estatística (ibGe), Censos Demográficos de i970, I980, I99I, 2000 E 2010 
QUADRO 2 | Brasil - Grau de urbanização segundo as macrorregióes, 1970-2010

\begin{tabular}{|l|c|c|c|c|c|}
\hline \multirow{2}{*}{\begin{tabular}{c}
\multirow{2}{*}{ UF ' } \\
BRASILEIRAS
\end{tabular}} & \multicolumn{5}{c|}{ GRAU DE URBANIZAÇÃo } \\
\cline { 2 - 6 } & $\mathbf{I 9 7 0}$ & $\mathbf{I 9 8 0}$ & $\mathbf{I 9 9 I}$ & $\mathbf{2 0 0 0}$ & $\mathbf{2 0}$ I0 \\
\hline Norte & 45,13 & 51,63 & 59,05 & 69,92 & 73,53 \\
\hline Nordeste & 41,82 & 50,46 & 60,65 & 68,98 & 73,13 \\
\hline Sudeste & 72,70 & 82,81 & 88,02 & 90,47 & 92,95 \\
\hline Sul & 44,29 & 62,40 & 74,12 & 80,92 & 84,93 \\
\hline Centro Oeste & 48,08 & 67,78 & 81,28 & 86,69 & 88,80 \\
\hline Total & 55,94 & 67,59 & 75,59 & 81,19 & 84,36 \\
\hline
\end{tabular}

FONTE IBGE, CENSOS DEMOGRÁFICOS DE I970, I980, I99I, 2000 E 20 IO

Outra característica da urbanização brasileira é a tendência para a concentração populacional em grandes cidades, principalmente naquelas localizadas em regióes metropolitanas (RMs). Em 1970, a população residente nas nove principais RMs brasileiras $^{1}$ era de 23.643 .734 habitantes, $25,39 \%$ da população total e 45,39\% da população urbana (Quadro 3). Entre 1970 e 2010 percebe-se um contínuo aumento da população residente nessas RMs, muito embora o incremento absoluto tenha sido decrescente e as participaçóes relativas dessa população -tanto sobre o total, quanto sobre a população urbana brasileira- tenham se reduzido, de forma relativamente acelerada, entre 1970 e 1991 e, de forma mais suavizada, a partir daquela data. Contribuíram para esse aumento as migraçóes internas, não apenas do tipo rural-urbana, mas também as migraçóes urbanas-urbanas inter e intraestaduais.

QUADRo 3 | Brasil - População total, urbana e das RMs, 1970-2010

\begin{tabular}{|c|c|c|c|c|c|c|c|c|c|}
\hline \multirow[b]{2}{*}{ PERÍODO } & \multicolumn{3}{|c|}{ POPULAÇÃO } & \multicolumn{3}{|c|}{ TAXA DE CRESCIMENTO } & \multirow[b]{2}{*}{$\begin{array}{c}\text { RM'S } \\
\text { BRASIL }\end{array}$} & \multirow{2}{*}{$\begin{array}{c}\text { RM'S } \\
\text { BRASIL } \\
\text { (URBA- } \\
\text { NA) }\end{array}$} & \multirow{2}{*}{$\begin{array}{c}\text { VARIAÇÁO } \\
\text { ABSOLUTA - } \\
\text { RM'S }\end{array}$} \\
\hline & $\begin{array}{l}\text { BRASIL } \\
\text { (TOTAL) }\end{array}$ & $\begin{array}{c}\text { BRASIL } \\
\text { (URBANA) }\end{array}$ & RM's & $\begin{array}{l}\text { BRASIL } \\
(\text { TOTAL) }\end{array}$ & $\begin{array}{c}\text { BRASIL } \\
\text { (URBA- } \\
\text { NA) }\end{array}$ & RM's & & & \\
\hline 1970 & 93.139 .037 & 52.084 .984 & 23.643 .734 & & & & 25,39 & 45,39 & \\
\hline 1980 & 119.002 .706 & 80.436 .409 & 34.411 .656 & 2,48 & 4,44 & 3,82 & 28,92 & 42,78 & 10.767 .922 \\
\hline 1991 & 146.825 .475 & 110.990 .990 & 42.798 .162 & 1,93 & 2,97 & 2,00 & 29,15 & 38,56 & 8.386 .506 \\
\hline 2000 & 169.872 .856 & 137.925 .238 & 51.088 .169 & 1,66 & 2,49 & 2,02 & 30,07 & 37,04 & 8.290 .007 \\
\hline 2010 & 190.755 .799 & 160.925 .792 & 57.049 .740 & 1,17 & 1,55 & 1,11 & 29,91 & 35,45 & 5.961 .571 \\
\hline
\end{tabular}

FONTE IBGE, CENSOS DEMOGRÁFICOS DE I970, I980, I99I, 2000 E 20 IO

A metropolização alcançou o seu ápice entre 1970 e 1980, quando o crescimento populacional do conjunto metropolitano atingiu a taxa de $3,82 \%$ ao ano. A partir daquele momento, percebe-se uma inflexão no ritmo de crescimento das RMs, seguindo a tendência de crescimento da população brasileira, desde os anos 19601970. Esta inflexão reflete, por um lado, o declínio da fecundidade, observado desde

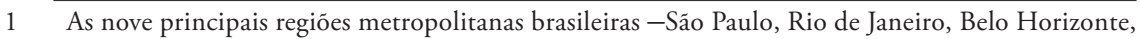
Salvador, Curitiba, Porto Alegre, Recife, Fortaleza e Belém- foram institucionalizadas de acordo com a Lei Federal no14 de 08-06-1973. 
meados dos anos 60, assim como a redução paulatina do poder de atração exercido por essas áreas. Apesar disso, as RMs permanecem como importantes destinos e continuam atraindo um enorme volume de migrantes, evidenciando a continuidade do processo de metropolização, embora em ritmo mais lento (Souza, 2008).

Para Baeninger (2000), a desaceleração da metropolização se faz perceber através da redução do ritmo de crescimento das RMs, da participação relativa da população residente em áreas metropolitanas na população urbana e na população total brasileira. Segundo o Censo de 2010, essas participaçóes relativas foram, respectivamente, 29,91\% e 35,45\% (Quadro 3).

Até os anos 60, esse processo foi marcado por um maior crescimento dos núcleos em relação às periferias, mas o Censo de 1970 revelou uma inversão espacial do crescimento demográfico metropolitano (Brito e Souza, 2005). Como se pode observar no Quadro 4, entre 1970 e 1980, com exceção de Fortaleza, nas demais regiôes metropolitanas a população residente na periferia metropolitana crescia a um ritmo significativamente mais acelerado, comparativamente aos respectivos núcleos. Observa-se, ainda, que, com exceção das RMs de Belém e do Rio de Janeiro, o ritmo de crescimento populacional dos municípios periféricos diminuiu ininterruptamente entre 1970 e 2010, ressaltando-se que, apesar dessa inflexão, o ritmo de crescimento da periferia se mantém mais acelerado que o crescimento dos núcleos metropolitanos. Significa que, assim como a metropolização, a periferização continua seguindo seu curso, embora mais lentamente.

As migrações intrametropolitanas cumprem, no processo de periferização, o mesmo papel crucial que as migraçóes intra e interestaduais (rurais-urbanas e urbanasurbanas) cumpriram -e continuam cumprindo- para a metropolização. Estimativas realizadas por Souza (2008), Cunha (1995), Pinho (2012), entre outros, utilizando os Censos Demográficos de 1991 e 2000, indicam que um grande e crescente número de indivíduos residentes nos núcleos das RMs muda de residência, tendo como destino, na maioria das vezes, outro município da própria região metropolitana.

QUADRO 4 | RM's - Ritmo de crescimento populacional dos núcleos e das periferias das principais RM's brasileiras, 1970-1980 e 2000-2010

\begin{tabular}{|l|c|c|c|c|c|c|c|c|}
\hline \multirow{2}{*}{$\begin{array}{c}\text { REGIÓES } \\
\text { METROPOLITANAS }\end{array}$} & \multicolumn{4}{|c|}{ NÚCLEO } & \multicolumn{5}{c|}{ PERIFERIA } \\
\cline { 2 - 9 } & I970-80 & I980-9I & I99I-00 & 2000-IO & I970-80 & I980-9I & I99I-00 & 2000-IO \\
\hline Belém & 3,95 & 2,65 & 0,31 & 0,85 & 9,26 & 5,36 & 14,29 & 3,24 \\
\hline Belo Horizonte & 3,73 & 1,15 & 1,11 & 0,59 & 7,45 & 5,11 & 3,97 & 1,65 \\
\hline Curitiba & 5,34 & 2,29 & 2,13 & 0,99 & 7,24 & 4,72 & 5,15 & 2,24 \\
\hline Fortaleza & 4,30 & 2,78 & 2,15 & 1,36 & 4,18 & 5,42 & 3,31 & 3,27 \\
\hline Porto Alegre & 2,43 & 1,06 & 0,83 & 0,35 & 5,30 & 3,71 & 2,16 & 1,05 \\
\hline Recife & 1,27 & 0,69 & 1,03 & 0,78 & 5,11 & 2,96 & 1,82 & 1,18 \\
\hline Rio de Janeiro & 1,82 & 0,67 & 0,74 & 0,76 & 3,39 & 1,49 & 1,66 & 0,91 \\
\hline Salvador & 4,08 & 2,98 & 1,84 & 0,91 & 6,91 & 4,31 & 3,62 & 4,50 \\
\hline São Paulo & 3,67 & 1,16 & 0,85 & 0,76 & 6,37 & 3,22 & 2,81 & 1,25 \\
\hline
\end{tabular}

FONTE IBGE, CENSOS DEMOGRÁFICOS DE I970, I980, I99I, 2000 E 20 IO 
Segundo Souza (2008), para a maioria dos migrantes intrametropolitanos, essa migração é, na realidade, a única oportunidade de manter residência na região metropolitana -onde se concentram os serviços e equipamentos urbanos- e de permanecer inserido no mercado de trabalho metropolitano -onde existem mais oportunidades de trabalho-. Segundo a autora, a maioria dos migrantes intrametropolitanos se dirige a cidades próximas ao núcleo, onde o mercado imobiliário e o custo de vida são mais acessíveis à população de baixa renda. É o que se denomina "periferização da pobreza". Por outro lado, como aponta Souza (2006), há também, embora em menor intensidade, a "periferização da riqueza", ou seja, a migração intrametropolitana de indivíduos de classes sociais mais elevadas, em busca da melhoria da qualidade de vida. Essas se expressam, principalmente, pela migração em direção aos condomínios fechados, caracterizados por grande disponibilidade de equipamentos urbanos, segurança interna, arborização etc.

Além da concentração populacional nas RMs e da periferização a ela associada, outra importante característica da urbanização brasileira é, nas palavras de Baeninger (2004, p.5), "o intenso processo de interiorização das aglomeraçôes urbanas". A interiorização do crescimento se inicia em São Paulo e no Rio de Janeiro, no final dos anos 60 e início dos anos 70, como uma resposta da dinâmica demográfica à desconcentração da atividade econômica, tornando-se mais pronunciada no final dos anos 70 e início dos anos 80 .

Segundo Baeninger (2000), o Censo de 1991 indicou, pela primeira vez, um crescimento populacional mais acelerado dos municípios de pequeno, médio e grande porte, ressaltando-se que, em 1970, alguns municípios de grande porte já vinham apresentando ritmo de crescimento populacional superior ao das Regióes Metropolitanas. Além disso, esse Censo revela, ainda, que a capacidade de absorçáo populacional exibida por esses municípios é elevada, tendo em vista o aumento da participação relativa da população residente nos mesmos, ao longo do tempo.

Segundo Baeninger (2004), além da desmetropolização da economia, também contribuíram para a interiorização o bom desempenho da agroindústria, a urbanização das áreas de fronteiras, o desenvolvimento da agricultura irrigada e os empreendimentos voltados para a exploraçáo dos recursos naturais, os quais criaram novas alternativas econômicas, frente à crise das metrópoles industrializadas. Pacheco (1997), apud Baeninger (2000), considera também que o desempenho das atividades agrícolas pode ter contribuído para uma retenção maior da população nas cidades pequenas. A esses motivos, acrescente-se o custo de vida relativamente alto nas áreas metropolitanas, destacando-se a dinâmica de seus mercados imobiliários, caracterizados por alta especulação financeira (Souza, 2008), a significativa melhoria da infraestrutura urbana das cidades de médio e grande porte, localizadas no interior do país (Matos e Ferreira, 2008), e a expansão das precariedades -como o aumento das deseconomias de aglomeração, carência de empregos e deterioração da qualidade de vida- nas grandes metrópoles (Matos, 2000). 
Uma importante manifestação da interiorização do crescimento é a criação de várias novas RMs em regiōes interioranas, ao longo das duas últimas décadas ${ }^{2}$. Segundo Ribeiro, Silva e Rodrigues (2011), em 31 de março de 2010, o Brasil tinha 35 RMs -incluindo as nove mais antigas- e três Regióes Integradas de Desenvolvimento (RIDEs) ${ }^{3}$. Segundo o IBGE (2010), atualmente são 51 RMs, três RIDEs e cinco Aglomeraçôes Urbanas. Além das novas RMs, Baeninger (2004) e Silva (2011) destacam o surgimento de novas espacialidades náo metropolitanas, como marco do processo de expansão urbana das duas últimas décadas.

Atualmente a rede urbana brasileira é formada por 5.565 municípios: 3.914 (70,3\%) de pequeno porte, $1.368(24,6 \%)$ de médio porte e $283(5,1 \%)$ de grande porte (Quadro 5).

QUADro 5 | Brasil - Rede urbana, segundo o número de municípios e a população residente, 2010

\begin{tabular}{|l|c|c|c|c|c|c|}
\hline $\begin{array}{c}\text { NÚMERO DE } \\
\text { HABITANTES }\end{array}$ & $\begin{array}{c}\text { NÚMERO DE } \\
\text { MUNICÍPIOS }\end{array}$ & $\begin{array}{c}(\%) \\
\text { SIMPLES }\end{array}$ & $\begin{array}{c}(\%) \\
\text { ACUMULADA }\end{array}$ & $\begin{array}{c}\text { POPULAÇÃO } \\
\text { RESIDENTE }\end{array}$ & $\begin{array}{c}(\%) \\
\text { SIMPLES }\end{array}$ & $\begin{array}{c}\text { (\%) } \\
\text { ACUMULADA }\end{array}$ \\
\hline Menos de $20 \mathrm{mil}$ & 3.914 & 70,3 & 70,3 & 32.660 .247 & 17,1 & 17,1 \\
\hline 20 a $50 \mathrm{mil}$ & 1.042 & 18,7 & 89,1 & 31.295 .175 & 16,4 & 33,5 \\
\hline 50 a $100 \mathrm{mil}$ & 326 & 5,9 & 94,9 & 22.363 .700 & 11,7 & 45,3 \\
\hline 100 a $500 \mathrm{mil}$ & 244 & 4,4 & 99,3 & 48.077 .609 & 25,2 & 70,5 \\
\hline Mais de $500 \mathrm{mil}$ & 39 & 0,7 & 100 & 56.359 .068 & 29,6 & 100 \\
\hline Total & 5.565 & 100 & - & $\mathbf{1 9 0 . 7 5 5 . 7 9 9}$ & $\mathbf{1 0 0}$ & - \\
\hline
\end{tabular}

FONTE SILVA, 20 I I

Se, por um lado, há um número relativamente alto de municípios de pequeno porte, por outro, observa-se a concentração populacional nos municípios de grande porte: em 2010, 104,4 milhóes de pessoas (54,8\% da população total brasileira) residia em municípios com mais de 100 mil habitantes, sendo que, entre estes, 53,3 milhóes $(53,96 \%)$ residiam em apenas 39 municípios, aqueles com mais de 500 mil habitantes. Entre estes, 22 são municípios metropolitanos, destacando-se as grandes metrópoles, e apenas 17 se localizam fora das RMs, sendo que 8 deles eram capitais estaduais.

Segundo Silva (2011), na última década houve uma redução da população absoluta residente em municípios com menos de 20 mil habitantes, ao passo que, os municípios não metropolitanos que cresceram mais aceleradamente foram aqueles com população superior a 500 mil habitantes (6,14\% a.a.) e, depois desses, aqueles com população entre 100 e 500 mil habitantes (1,57\% a.a.). Para a autora, apesar de

2 A CF/88 transferiu para os governos estaduais e municipais a competência para criar e delimitar RMs. Um dos problemas desta transferência é que as UFs têm legislaçôes próprias e, por esse motivo, as novas RMs diferem significativamente umas das outras. Além disso, muitas vezes a criação de uma RM relaciona-se mais a fatores políticos do que ao grau de interação socioeconômica entre os municípios.

3 Segundo o Ministério da Integração Nacional "as RIDEs têm como objetivo articular e harmonizar as açôes administrativas da União, dos Estados e dos Municípios para a promoção de projetos que visem a dinamização econômica de territórios de baixo desenvolvimento" (www.mi.gov.br, acesso em 17/09/2012). 
não estarem inseridos em regióes metropolitanas, esses núcleos urbanos são capazes de se organizar em redes e sub-redes de cidades e, alguns deles -como São José dos Campos, por exemplo- mantêm uma forte relação com a metrópole mais próxima.

Com base nesses resultados, é possível afirmar que, ao mesmo tempo em que a interiorização do crescimento revela um processo de desconcentração metropolitana que se manifesta, inclusive, pela redução da participação relativa da população, residente em algumas das principais RMs -São Paulo e Rio de Janeiro- no total da população estadual (Baeninger, 2000), há uma "desconcentração concentrada" nos municípios de grande porte, principalmente naqueles com mais de 500 mil habitantes e nas novas RMs. Estas, na última década, cresceram mais aceleradamente do que as RMs mais antigas, embora não tenham alcançado as taxas mais elevadas exibidas pelas primeiras (Silva, 2011).

Segundo Baeninger (2000), na região Sudeste, o processo de interiorização do crescimento revelou-se mais acelerado, comparativamente às demais regióes brasileiras. Santos e Campinas, as primeiras metrópoles interioranas do país, surgiram a partir da desconcentração espacial da indústria paulista. Essa mesma desconcentraçáo propiciou o desenvolvimento de Uberaba e Uberlândia, no Triângulo Mineiro, e de Varginha, Poços de Caldas e Pouso Alegre, no Sul de Minas. No Espírito Santo, a interiorizaçáo do crescimento se fez notar pelo desenvolvimento de Linhares, Colatina e Cachoeiro do Itapemirim.

No Rio de Janeiro, a descentralização da atividade econômica, também iniciada nos anos 70, resultou na formação das aglomeraçóes urbanas de Barra Mansa/Volta Redonda, Cabo Frio, e intensificou o processo de interiorizaçáo em direção aos centros urbanos de Macaé, Campos de Goytacazes, Nova Friburgo, Petrópolis e Teresópolis (Baeninger, 2003). No caso específico do Norte Fluminense -aglomeraçóes urbanas de Macaé e Campos dos Goytacazes- a intensificaçáo do processo de interiorização relaciona-se à descoberta de petróleo na Bacia de Campos, no início dos anos 70, à instalação da Petrobras, em Macaé, em 1974, e ao início das atividades de exploração, em 1977.

No entanto, Fernandes, Terra e Campos (2012) ressaltam que, como os impactos da atividade petrolífera extrapolam a delimitação geográfica do norte fluminense, torna-se imprescindível, para efeitos analíticos das mudanças sociais, econômicas e demográficas que têm lugar na região, a adoção de uma nova configuração espacial, a ser discutida na próxima seção.

\section{Ompetro: formação e expansáo urbana}

A Organização dos Municípios Produtores de Petróleo e Gás Natural e Limítrofes da Zona de Produção Principal da Bacia de Campos (Ompetro), fundada em 2001, inclui municípios do Norte Fluminense e das Baixadas Litorâneas, além de Niterói na Região Metropolitana, e exclui outros municípios interioranos dessas regióes. Todos os municípios membros apresentam, em comum, a característica de serem considerados produtores de petróleo pela Agência Nacional do Petróleo (ANP).

Atualmente participam da Ompetro os municípios de Armação de Búzios, Arraial do Cabo, Cabo Frio, Campos dos Goytacazes, Carapebus, Casimiro de 
Abreu, Macaé, Niterói, Quissamã, Rio das Ostras e São João da Barra (Figura 1). O principal objetivo da organização é representar os municípios no Conselho Nacional de Política Energética, assim como nas discussóes sobre a exploração e produção de petróleo, realizadas pelo governo do Estado do Rio de Janeiro.

\section{FIGURA I | Municípios pertencentes à Ompetro, 2012}

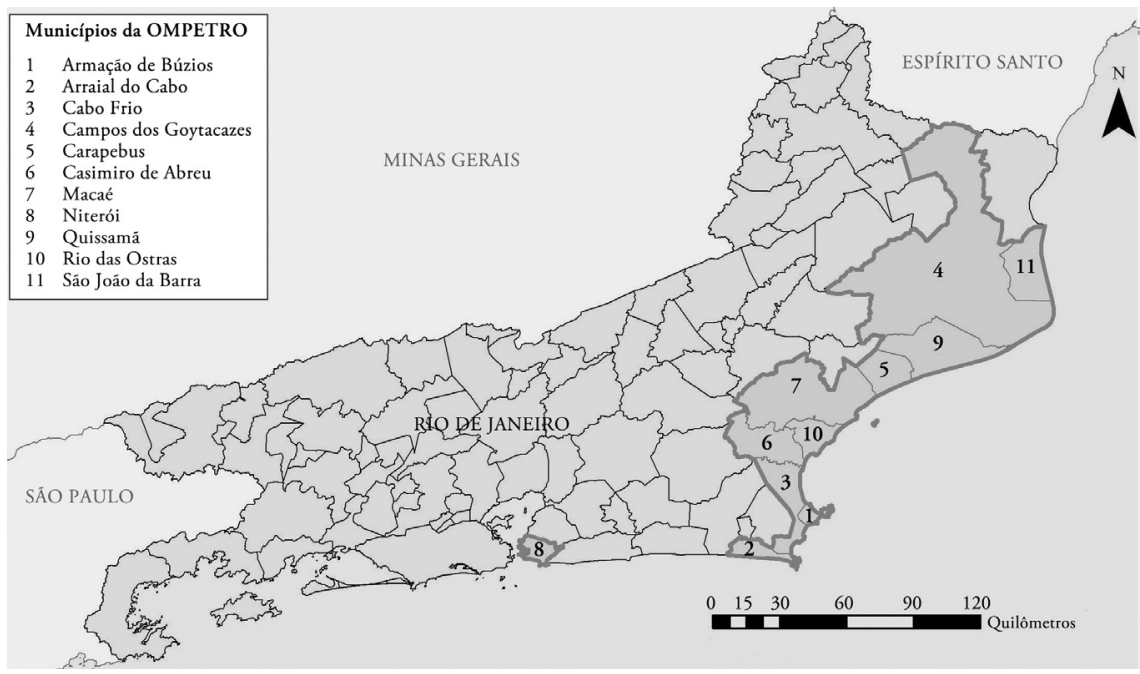

FONTE IBGE, CENSO DEMOGRÁFICO DE 20 IO

A concentração de mais de $80 \%$ da produção nacional de petróleo e gás na Bacia de Campos resultou na conformação de uma região composta por municípios "petrorentistas” com recursos diferenciados em relação à média dos demais municípios brasileiros. Esses municípios são os maiores beneficiários das compensaçóes financeiras do setor petrolífero (royalties e participaçóes especiais), o que os coloca em situação privilegiada diante da maioria dos municípios brasileiros de mesmo porte. A título de ilustração, em 2011, 1.031 municípios brasileiros (18,5\%) eram beneficiários das rendas petrolíferas e receberam uma receita total de $\mathrm{R} \$ 5,443$ bilhóes provenientes de royalties e participaçôes especiais (Quadro 6). É notória a concentração de 64,95\% desses recursos em 87 municípios fluminenses - principalmente, naqueles pertencentes à Ompetro-. Entre eles, os maiores beneficiários das rendas petrolíferas são: Campos dos Goytacazes, que sozinho recebeu $\mathrm{R} \$ 1,051$ bilhão (40,44\% do total da renda petrolífera da região), Macaé (17,83\%) e Rio das Ostras (11,10\%).

QUADRO 6 | Brasil - Distribuição das rendas petrolíferas entre municípios, 2011

\begin{tabular}{|l|c|c|c|c|c|}
\hline $\begin{array}{c}\text { DISTRIBUIÇÓ́ES DAS } \\
\text { RENDAS PETROLÍ́FERAS }\end{array}$ & $\begin{array}{c}\text { NÚMERO DE } \\
\text { BENEFICIÁRIOS }\end{array}$ & ROYALTIES & $\begin{array}{c}\text { PARTICIPAÇÓES } \\
\text { ESPECIAIS }\end{array}$ & TOTAL & (\%) \\
\hline Municípios do Brasil & 1.031 & 4.441 .624 .101 & 1.002 .085 .199 & 5.443 .709 .300 & 100,00 \\
\hline Municípios do RJ & 87 & 2.659 .886 .211 & 875.950 .389 & 3.535 .836 .600 & 64,95 \\
\hline Municípios da Ompetro & 11 & 1.725 .526 .503 & 875.950 .389 & 2.601 .476 .892 & 47,79 \\
\hline
\end{tabular}

FONTE ELABORADA A PARTIR DE DADOS DA ANP. WWW.ROYALTIESDOPETROLEO.UCAM-CAMPOS.BR 
A maior parte destes municípios tem enfrentado significativas transformaçóes demográficas, territoriais, econômicas, sociais, políticas e culturais relacionadas, principalmente, ao grande volume de recursos provenientes dos royalties e participaçóes especiais. Com maior dinamismo econômico, alguns desses municípios, antes expulsores de populaçáo, vêm se tornando mais atrativos para a população migrante, principalmente para aquela à procura de novas e melhores oportunidades no mercado de trabalho. Outro efeito não menos importante do maior dinamismo econômico é a elevação do poder de retenção populacional por parte desses municípios.

Os municípios selecionados, que em 1980 possuíam 905.641 habitantes, contabilizavam, em 2010, 1.606 .894 habitantes, o que correspondia a 10,5\% da população do Estado. Observa-se, no Quadro 7, que desde os anos 80 esta regiáo vem apresentando ritmo de crescimento médio anual superior à média estadual, e que ele vem-se tornando mais acelerado, tendo aumentado de 1,64\% entre 19801991, para 1,88\% entre 1991-2000, e para 2,33\%, entre 2000-2010. Como reflexo dessa aceleraçáo, a participaçáo relativa dos municípios da Ompetro no incremento populacional absoluto do Rio de Janeiro aumentou de 12,4\%, entre 1980-1991, para 20,66\% no período 2000-2010.

QUAdro 7 | Rio de Janeiro e Ompetro - População, Taxa de crescimento e participação relativa no incremento absoluto, 1980-2010

\begin{tabular}{|c|c|c|c|c|}
\hline \multicolumn{5}{|c|}{ POPULAÇÃO } \\
\hline LOCALIDADE & 1980 & I99I & 2000 & 2010 \\
\hline Ompetro & 905.641 & 1.083 .116 & 1.276 .582 & 1.606 .894 \\
\hline Rio de Janeiro & 11.378 .796 & 12.807 .706 & 14.391 .282 & 15.989 .929 \\
\hline Ompetro/RJ & 7,96 & 8,46 & 8,87 & 10,05 \\
\hline \multicolumn{4}{|c|}{ TAXA DE CRESCIMENTO } & \\
\hline & $1980-1991$ & $1991-2000$ & $2000-2010$ & \\
\hline Ompetro & 1,64 & 1,88 & 2,33 & \\
\hline Rio de Janeiro & 1,08 & 1,33 & 1,06 & \\
\hline \multicolumn{4}{|c|}{ PARTICIPAÇÁO RELATIVA NO INCREMENTO ABSOLUTO } & \\
\hline & 1980-1991 & $1991-2000$ & $2000-2010$ & \\
\hline Ompetro-RJ & 12,42 & 12,22 & 20,66 & \\
\hline
\end{tabular}

FONTE IBGE, CENSOS DEMOGRÁFICOS DE I980, I99I, 2000 E 20 IO

Vale ressaltar que os ritmos de crescimento variaram significativamente entre os municípios da Ompetro, entre 1980 e 2010. Nos anos 80, cresceram mais aceleradamente os municípios de Rio das Ostras (5,54\%), Macaé (4,18\%) e Cabo Frio (3,99\%). No período 1991-2000, com exceção de Arraial do Cabo, Campos, Niterói e Macaé, verifica-se nos demais municípios uma aceleração no ritmo de crescimento, destacando-se Búzios (8,85\%), Rio das Ostras (8,17\%) e Cabo Frio (5,95\%). Entre 2000-2010, com exceção de 4 municípios -Búzios, Arraial do Cabo, Cabo Frio e São Joáo da Barra- em todos os outros a taxa de crescimento populacional aumentou em relação ao período 1991-2000, As maiores variaçóes se 
verificaram em Carapebus e Rio das Ostras, cujas taxas de crescimento se elevaram de 2,06\% e 8,17\%, entre 1991-2000, para 4,42\% e 11,24\%, respectivamente. Búzios e Cabo Frio, apesar de terem experimentado um arrefecimento em seu ritmo de crescimento, continuaram entre aqueles de crescimento populacional acelerado.

A intensa expansão urbana pela qual vem passando esta região, a exemplo do que ocorreu e continua ocorrendo nas RMs, é fortemente alimentada pelas migraçóes internas. Observa-se, no Quadro 8, que os municípios pertencentes à Ompetro vêm atraindo um número cada vez maior de imigrantes, principalmente de outros municípios do próprio Estado do Rio de Janeiro. Em números absolutos, verifica-se também um aumento do número de imigrantes interestaduais -embora a participação relativa destes tenha reduzido ao longo do período- e dos imigrantes internacionais - que permanecem representando uma parcela ínfima dos fluxos migratórios naquela direção.

QUADRO 8 | Ompetro - Imigrantes segundo a origem, 1986-1991 e 1995-2000

\begin{tabular}{|l|c|c|c|c|c|c|}
\hline \multirow{2}{*}{ ORIGEM } & \multicolumn{7}{|c|}{ PERÍODO } \\
\cline { 2 - 7 } & I986-I99I & \% & I995-2000 & (\%) & 2000-20IO & (\%) \\
\hline Intraestadual & 56.711 & 73,17 & 86.604 & 75,37 & 162.358 & 77,78 \\
\hline Interestadual & 20.014 & 25,82 & 26.656 & 23,20 & 44.006 & 21,08 \\
\hline Internacional & 786 & 1,01 & 1.643 & 1,43 & 2.365 & 1,13 \\
\hline Total & 77.511 & 100,00 & 114.903 & 100,00 & 208.729 & 100,00 \\
\hline
\end{tabular}

FONTE FERNANDES, TERRA E CAMPOS, 20 I 2

Os Censos revelam, também, significativos e crescentes fluxos migratórios entre os municípios da Ompetro (esses imigrantes estão incluídos nos dados da Quadro 8 como imigrantes intraestaduais). Do total de imigrantes intraestaduais, entre 1986-1991, $11.501(20,28 \%)$ eram indivíduos que, na data fixa (31/07/1986) residiam em algum município da própria Ompetro, fora daquele em que residia no ano censitário. No quinquênio 1995-2000, foram 20.124 imigrantes internos à Ompetro (20,24\% dos imigrantes intraestaduais), tendo esse número aumentado para 29.459 (18,14\%), indivíduos no quinquênio 2005-2010. Esta migração não altera a população regional absoluta, mas reflete o processo de segregação socioespacial da população ali residente, altera a distribuição espacial da população entre aqueles municípios e influencia nos ritmos de crescimento de cada um deles. Por sua natureza e magnitude e por estarem intrinsecamente relacionados ao processo de expansão urbana regional, devem ser melhor pesquisados mas, por ora, tendo em vista os objetivos propostos, apenas sua magnitude será destacada.

Além das informaçôes sobre as migraçóes intraestaduais (inclusive internas a determinada regiāo) e interestaduais, segundo Moura, Castello Branco e Firkowski (2005) e Pereira e Herrero (2009), as informaçôes sobre os movimentos pendulares são também imprescindíveis para a análise dos processos de expansão dos aglomerados urbanos, uma vez que refletem as características e o grau de integração urbana de determinada região. No Brasil, tais informações são utilizadas, inclusive, para a delimitação -e reconfiguração- das RMs e, mais recentemente, vêm sendo usadas 
também para a delimitação das novas espacialidades, ou seja, das novas áreas de expansão urbana.

Segundo Moura, Castello Branco e Firkowski (2005), entende-se por movimento pendular "a mobilidade correspondente ao conjunto de deslocamentos que o indivíduo efetua para executar os atos de sua vida cotidiana (trabalho, compras, lazer)" (p. 122). Esses movimentos são substancialmente diferentes dos movimentos migratórios, os quais, por definição, implicam transferência -permanente ou semipermamente- de residência entre os locais de origem e destino. Em suma, o termo se refere aos movimentos populacionais cotidianos que não envolvem mudanças de residência entre a origem e o destino, sendo o destino final o próprio lugar de origem do indivíduo. Apesar de sua natureza temporária e breve, os movimentos pendulares são "capazes de transformar a cidade anterior, compondo, recompondo e decompondo novos territórios" (idem).

\section{Materiais e métodos para análise da pendularidade}

A mobilidade pendular entre os municípios da Ompetro será analisada a partir dos Censos Demográficos de 2000 e 2010, pressupondo-se que os movimentos pendulares tendem a recrudescer entre municípios interioranos, principalmente naquelas áreas reconhecidas como novas territorialidades, no processo de expansão urbana brasileiro.

Com as informaçóes do Censo Demográfico de 2000, é possível identificar o número de indivíduos que trabalhavam e/ou estudavam em outro município. Para aqueles que declararam trabalhar e estudar em outro município, registrou-se o nome do município, da UF ou do país estrangeiro onde o indivíduo trabalhava ou estudava. Nesse Censo o IBGE admite, como deslocamento pendular, aquele que "uma pessoa realiza entre seus locais de residência e de trabalho/estudo, quando estes se localizam em municípios distintos” (Pereira \& Herrero, 2009, p. 9).

O Censo de 2010 apresenta avanços significativos nas informaçôes sobre os movimentos pendulares. O primeiro deles é a separação da pendularidade segundo o motivo -trabalho ou estudo-. Para aqueles que estudam fora, perguntou-se o nome do município e da UF ou o nome do país estrangeiro onde se localiza o estabelecimento de ensino. Para aqueles que trabalham em município diferente daquele de residência, perguntou-se, além do nome do município e da UF ou do país estrangeiro onde trabalha, se o indivíduo retorna para casa diariamente e qual o tempo habitualmente gasto no deslocamento do domicílio até o local do trabalho principal. Note-se que, pelas informaçóes do Censo de 2010, é possível analisar a pendularidade em seu sentido mais estrito.

Para se analisar a interação socioeconômica entre os municípios pertencentes à Ompetro, será feita uma análise comparativa, utilizando-se as informaçóes dos Censos Demográficos de 2000 e 2010, referentes à pendularidade por motivo trabalho, o principal responsável pela mobilidade diária de um número expressivo de indivíduos. Serão identificadas, em cada Censo, a população em idade ativa (PIA) e a população economicamente ativa (PEA), assim como o local de trabalho para a populaçáo com 10 anos ou mais de idade. 
De forma a permitir a comparação, do Censo de 2000 serão excluídas as informações de pendularidade referentes às pessoas que não trabalham e só estudam, e mantidas as informaçóes apenas para aqueles que trabalham, lembrando que, nesse Censo, para aqueles que trabalham e estudam, foi registrado apenas o nome do município de trabalho, o que evita a dupla contagem e a sobreenumeração dos fluxos. A partir dessas informaçóes serão identificados, em cada período, os principais fluxos e, portanto, os principais municípios de origem e destino, bem como os saldos dos movimentos pendulares.

O Censo de 2010 permitirá analisar, ainda, os fluxos pendulares por motivo trabalho, que ocorrem diariamente entre os municípios da Ompetro. Como se mencionou, para efeitos desta análise, serão considerados pendulares apenas os indivíduos que trabalham em município diferente do de residência, e que retornam diariamente para ele após a jornada de trabalho. Para os fluxos mais importantes serão analisadas as estruturas etárias, assim como o nível de escolaridade e de rendimento daqueles que os compóem, além dos principais setores de atividade e ocupaçóes em que esses indivíduos se encontram inseridos nos mercados de trabalho de destino. Esses resultados devem apontar os processos de seletividade dos fluxos pendulares, assim como fornecer subsídios para a análise da especialização do espaço regional.

Ressalte-se ainda que, nas análises a serem realizadas neste artigo, serão considerados todos os trabalhadores pendulares nos municípios da Ompetro, independentemente de seu status migratório.

\section{Análise dos resultados}

De acordo com o Censo Demográfico de 2000, a Ompetro contava, naquele ano, com uma população de 1.276.582 habitantes, entre os quais 1.064 .431 em idade ativa, ou seja, com 10 anos ou mais de idade. Entre 2000 e 2010, a população residente nesta regiáo cresceu a um ritmo médio anual de $2,33 \%$, enquanto a população fluminense cresceu, em sua totalidade, a uma taxa de 1,06\% ao ano. A taxa de crescimento da PIA, de 2,73\% ao ano (Quadro 9), superior à média regional e estadual, reflete possíveis reduçóes de mortalidade entre os períodos, mas, principalmente, a influência -seletiva por idade- dos movimentos migratórios que, como vimos, aumentaram durante o período considerado.

É notável a expansão da PIA de Rio das Ostras (variação relativa de 202,83\% entre 2000 e 2010, e taxa de crescimento de $11,72 \%$ ao ano). Destaca-se, ainda, o elevado crescimento da pia de Casimiro de Abreu, Macaé, Armação de Búzios, Carapebus, Cabo Frio e Quissamã. Em 2010, a PIA residente nos municípios da Ompetro era de 1.393 .996 pessoas $(86,75 \%$ da população total residente na região).

Entre 2000 e 2010, excetuando-se Armação de Búzios e Campos dos Goytacazes, nos demais municípios o ritmo de crescimento da PEA foi maior do que o da PIA, indicando uma expansão do mercado de trabalho da região (Gráfico 1). A PEA, que era $592.702(55,68 \%$ da PIA), em 2000, aumentou para 799.508 pessoas (57,35\% da PIA), em 2010, tendo apresentado uma variação absoluta de 206.805 indivíduos, uma variação relativa de $34,89 \%$, e uma taxa de crescimento média anual de 3,04\% (Quadro 10). 


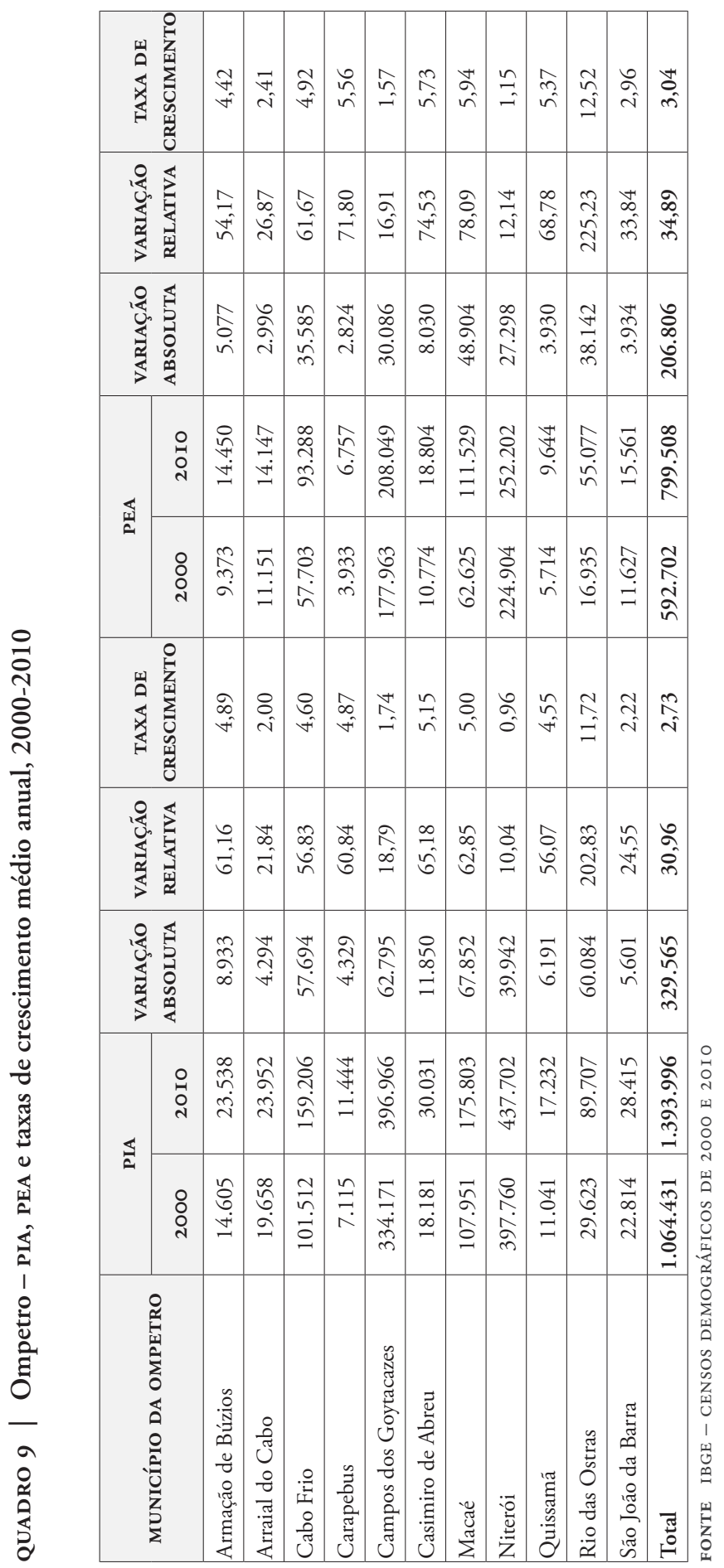


GRÁfico I| Ompetro - taxas de crescimento da PIA e da PEA, segundo os municípios, 2000-2010

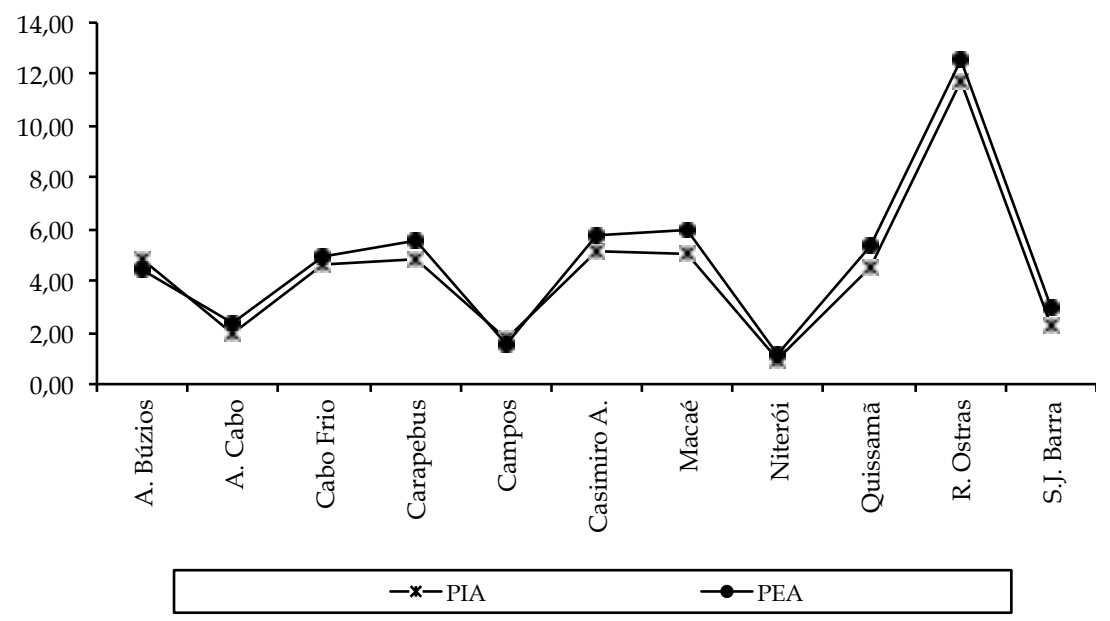

FONTE IBGE - CENSOS DEMOGRÁFICOS DE 2000 E 2010

A taxa de desemprego -dada pelo quociente entre o total de desempregados e o total da PEA- encontrava-se, em 2000, em torno de $15 \%$, índice maior que o da média nacional, estimada em 11,6\%. Entre 2000 e 2010, os municípios pertencentes à Ompetro geraram, em média, mais empregos do que a economia brasileira em seu conjunto, registrando, em 2010, um desemprego em torno de 8,8\% da PEA, enquanto a média nacional era de 9,4\% (IPEADATA, acesso em 18/09/2012). A redução da taxa de desemprego foi compensada, principalmente, pelo aumento da participaçáo relativa dos trabalhadores remunerados na PEA de 82,62\% (489.715 trabalhadores), em 2000, para 86,86\% (694.415), em 2010.

Tanto em 2000 quanto em 2010, a maioria dos trabalhadores -formais e informais- trabalhava no próprio município de residência, mas é interessante observar a variação do número de trabalhadores pendulares, ou seja, do número daqueles que declararam, em cada Censo, trabalhar em município diferente do município de residência: em 2000, eram 70.250 trabalhadores pendulares $(14,35 \%$ do total de trabalhadores remunerados); em 2010, 125.546 (18,08\%) pessoas. Entre os pendulares, prevalecem, nos dois períodos, aqueles que trabalham em outro município do próprio Estado do Rio de Janeiro: em 2000, 69.086 indivíduos (14,11\% do total de trabalhadores remunerados e 98,34\% dos trabalhadores pendulares daquele período); em 2010, 115.818 (16,68\% do total e 94,66\% dos pendulares) (Gráfico 2). Esses resultados reforçam o fato de que a proximidade espacial é um importante determinante dos movimentos pendulares.

Foram confeccionadas as matrizes Origem-Destino para 2000 e 2010 , com as informaçóes censitárias referentes aos movimentos pendulares, considerando-se os municípios da Ompetro. Utilizando-se de tais matrizes, identificam-se as principais 
áreas alimentadoras dos fluxos pendulares, assim como as novas centralidades de absorção dessa mão de obra. Por convenção, na confecção das matrizes $\mathrm{O}-\mathrm{D}$, temos, nas linhas, os locais de origem (nesse caso o município de residência) e nas colunas, os destinos (nesse caso o município onde o indivíduo trabalha). Como na diagonal principal estariam todos os indivíduos que trabalham no mesmo município de residência e, trabalha-se apenas com os pendulares, ela se apresenta nula em toda a sua extensão. Seus principais resultados encontram-se resumidos no Quadro 11, lembrando que o saldo pendular é dado pela diferença entre as Entradas e as Saídas registradas em um mesmo município, em cada período.

GRÁfICO 2 | Ompetro - Local de trabalho dos trabalhadores remunerados, 2000-2010

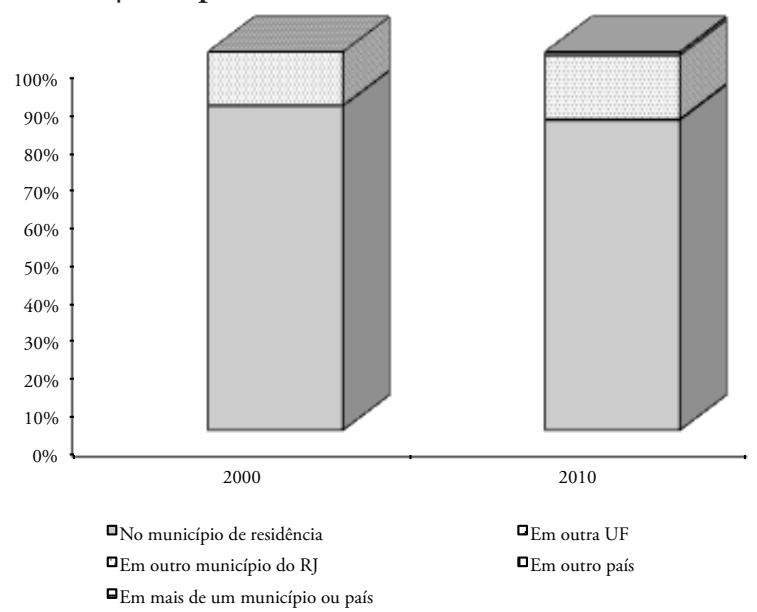

FONTE IBGE - CENSOS DEMOGRÁFICOS DE 2000 E 20 IO

QUADRo Io| Ompetro - Mobilidade pendular, 2000-2010

\begin{tabular}{|l|r|r|r|r|r|c|}
\hline \multirow{2}{*}{$\begin{array}{c}\text { MUNICíPIO DA } \\
\text { OMPETRo }\end{array}$} & \multicolumn{3}{|c|}{ 2000 } & \multicolumn{3}{c|}{ 20IO } \\
\cline { 2 - 7 } & ENTRADAS & SAÍDAS & $\begin{array}{c}\text { SALDO } \\
\text { PENDULAR }\end{array}$ & ENTRADAS & SAÍDAS & $\begin{array}{c}\text { SALDO } \\
\text { PENDULAR }\end{array}$ \\
\hline Armação de Búzios & 2.587 & 203 & 2.384 & 5.440 & 309 & 5.131 \\
\hline Arraial do Cabo & 517 & 865 & -348 & 528 & 1.478 & -950 \\
\hline Cabo Frio & 1.301 & 4.036 & -2.735 & 2.205 & 10.606 & -8.401 \\
\hline Carapebus & 188 & 497 & -309 & 224 & 2.297 & -2.073 \\
\hline Campos dos Goytacazes & 1.241 & 3.667 & -2.426 & 2.507 & 8.174 & -5.667 \\
\hline Casimiro de Abreu & 609 & 1.079 & -470 & 1.489 & 3.817 & -2.328 \\
\hline Macaé & 5.760 & 502 & 5.258 & 25.004 & 974 & 24.030 \\
\hline Niterói & 426 & 465 & -39 & 516 & 1.223 & -707 \\
\hline Quissamã & 177 & 527 & -350 & 351 & 1.139 & -788 \\
\hline Rio das Ostras & 886 & 1.217 & -331 & 4.057 & 12.208 & -8.151 \\
\hline São João da Barra & 327 & 961 & -634 & 1.321 & 1.417 & -96 \\
\hline Total & $\mathbf{1 4 . 0 1 9}$ & $\mathbf{1 4 . 0 1 9}$ & $\mathbf{0}$ & $\mathbf{4 3 . 6 4 2}$ & $\mathbf{4 3 . 6 4 2}$ & $\mathbf{0}$ \\
\hline
\end{tabular}

FONTE IBGE - CENSOS DEMOGRÁFICOS DE 2000 E 2010 
Como se pode notar no Quadro 10, Macaé foi o município que registrou as maiores entradas, nos dois períodos analisados, ressaltando-se que esse número mais do que quadruplicou, entre 2000 e 2010 . Por outro lado, as saídas registradas naquele município são inexpressivas nos dois períodos e, em termos relativos, seu incremento foi significativamente menor, comparativamente ao incremento das entradas, resultando em um saldo pendular, em 2010, de aproximadamente 4,5 vezes maior do que o saldo pendular estimado para 2000. Esses resultados se explicam pela concentração da atividade econômica nesse município, principalmente daquela voltada para exploração e beneficiamento do petróleo, o que torna o seu mercado de trabalho mais amplo, capaz de absorver grande parte da máo de obra lá residente, e também um elevado e crescente número de trabalhadores residentes em outros municípios da Ompetro.

Em 2000, destacam-se também como importantes destinos: Armação de Búzios, Cabo Frio, Campos dos Goytacazes e, em 2010, inclui-se nesse grupo o município de Rio das Ostras. No entanto, além de Macaé, saldos pendulares positivos só foram verificados em Armação de Búzios: uma entrada líquida de 2.384 trabalhadores, em 2000, e de 5.131, em 2010. Significa dizer que, apesar de se destacarem pelas entradas expressivas, os demais municípios apresentam saldos pendulares negativos, porque deles saíam um número ainda mais expressivo de trabalhadores. Segundo o Censo de 2000, praticamente 55\% dos trabalhadores pendulares dos municípios da Ompetro residiam em Cabo Frio e em Campos.

Apesar do significativo aumento dos registros de saída, a partir desses municípios, e da permanência dos mesmos como importantes áreas de origem dos movimentos pendulares intraregionais, eles perderam importância relativa principalmente para Rio das Ostras, de onde partiram 27,97\% dos trabalhadores pendulares, segundo o Censo de 2010. A combinação dessa informação com a taxa de crescimento populacional desse município, no período 2000-2010, permite inferir que parte do crescimento populacional de Rios das Ostras é, na realidade, induzido pelo dinamismo econômico de Macaé.

O município de São João da Barra, apesar de registrar um número relativamente baixo de entradas e saídas nos dois períodos apresentou, diferentemente dos demais, uma redução em seu saldo pendular negativo. Isso possivelmente se deve às obras de construção do Porto de Açu, que ampliou o número de pessoas ocupadas no setor de construção civil, naquele município.

Niterói, o maior município da Ompetro -com uma população de 487.562 habitantes, em 2010- apresenta, nos dois períodos, fluxos pendulares de baixa densidade com os demais municípios da Ompetro. Este município faz parte da Região Metropolitana do Rio de Janeiro e sua maior interação é, de fato, com a capital fluminense: em 2000, 21,2\% do total de trabalhadores remunerados residentes naquele município trabalhavam na cidade do Rio de Janeiro, tendo esse percentual se elevado para $22,6 \%$, em 2010.

Segundo o Censo de 2010, entre os 43.642 trabalhadores que declararam trabalhar em outro município pertencente à Ompetro, 31.611 (72,43\%) retornavam para casa diariamente. Os fluxos diários estão retratados na Matriz 1, e seguem o padrão anteriormente descrito. No entanto, essa informação torna-se imprescindível para efeitos de planejamento, principalmente do setor de transporte intrarregional. 
Observa-se que, a quase totalidade dos trabalhadores pendulares de Armação de Búzios são provenientes de Cabo Frio, enquanto mais da metade dos pendulares de Macaé são residentes em Rio das Ostras, sendo de média densidade os fluxos de Cabo Frio, Carapebus, Campos dos Goytacazes e Casimiro de Abreu em direção àquele município.

Matriz 1 | Ompetro - Origem-Destino dos trabalhadores pendulares dos fluxos diários, 2010

\begin{tabular}{|c|c|c|c|c|c|c|c|c|c|c|c|c|c|}
\hline & \multicolumn{12}{|c|}{ MUNICÍPIO ONDE TRABALHA } \\
\hline & & $\begin{array}{l}\text { A. } \\
\text { Búzios }\end{array}$ & $\begin{array}{c}\text { A. } \\
\text { Cabo }\end{array}$ & $\begin{array}{c}\text { Cabo } \\
\text { Frio }\end{array}$ & $\begin{array}{l}\text { Cara- } \\
\text { pebus }\end{array}$ & $\begin{array}{c}\text { Cam- } \\
\text { poss }\end{array}$ & $\begin{array}{c}\text { C. } \\
\text { Abreu }\end{array}$ & Macaé & Niterói & $\begin{array}{l}\text { Quis- } \\
\text { samãa }\end{array}$ & $\begin{array}{c}\text { R. } \\
\text { Ostras }\end{array}$ & $\begin{array}{c}\text { S.J. } \\
\text { Barra }\end{array}$ & Total \\
\hline & A. Búzios & 0 & 12 & 240 & 0 & 0 & 0 & 0 & 0 & 0 & 11 & 0 & 263 \\
\hline & A. Cabo & 38 & 0 & 937 & 0 & 0 & 10 & 65 & 0 & 0 & 0 & 0 & 1.050 \\
\hline$\leq$ & \begin{tabular}{|l|} 
Cabo \\
Frio \\
\end{tabular} & 4.992 & 463 & 0 & 0 & 21 & 677 & 1.729 & 75 & 0 & 1.320 & 0 & 9.277 \\
\hline 焉 & $\begin{array}{l}\text { Carape- } \\
\text { bus }\end{array}$ & 6 & 0 & 0 & 0 & 24 & 0 & 1.823 & 0 & 54 & 23 & 0 & 1.930 \\
\hline 离 & Campos & 0 & 0 & 40 & 11 & 0 & 11 & 1.590 & 26 & 154 & 21 & 1.057 & 2.910 \\
\hline 용 & C. Abreu & 18 & 0 & 249 & 0 & 17 & 0 & 1.187 & 10 & 0 & 1.881 & 0 & 3.362 \\
\hline$\stackrel{0}{0}$ & Macaé & 10 & 0 & 25 & 34 & 113 & 47 & 0 & 10 & 11 & 343 & 8 & 601 \\
\hline ") & Niterói & 10 & 0 & 41 & 0 & 30 & 8 & 144 & 0 & 0 & 22 & 0 & 255 \\
\hline 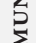 & Quissamã & 0 & 0 & 0 & 136 & 86 & 0 & 384 & 0 & 0 & 5 & 0 & 611 \\
\hline & R. Ostras & 29 & 0 & 304 & 7 & 38 & 583 & 9.250 & 63 & 16 & 0 & 8 & 10.298 \\
\hline & S.J. Barra & 0 & 0 & 0 & 0 & 1.009 & 0 & 45 & 0 & 0 & 0 & 0 & 1.054 \\
\hline & Total & 5.103 & 475 & 1.836 & 188 & 1.338 & 1.336 & 16.217 & 184 & 235 & 3.626 & 1.073 & 31.611 \\
\hline
\end{tabular}

FONTE IBGE - CENSO DEMOGRÁFICO DE 2010

Considerando-se apenas os que retornavam para casa diariamente, há predomínio de homens (61,4\% de homens e 38,6\% de mulheres) e de indivíduos mais jovens (86,92\% tinham entre 15 e 49 anos de idade) como se pode notar no Gráfico 3 .

As estruturas etárias dos fluxos pendulares em direção a Macaé e Búzios, os únicos que apresentaram saldos pendulares positivos e que, por esse motivo, serão enfatizados nas análises, encontram-se no Gráfico 4. Embora nos dois fluxos haja predomínio de homens e de jovens, são significativas as diferenças entre eles. $\mathrm{O}$ fluxo pendular em direção a Macaé era composto por $66,4 \%$ de homens e $33,56 \%$ de mulheres; para Búzios, esses percentuais são, respectivamente, 60,30\% e 39,70\%. Essas diferenças se relacionam às características dos mercados de trabalho daqueles dois municípios: Macaé, a capital do Petróleo, atrai muitos trabalhadores para o setor industrial, enquanto em Armação de Búzios a maior atratividade é exercida pelo setor de turismo que, pela natureza de suas ocupaçóes, absorve com maior facilidade a mão de obra feminina. 
GRÁFICO 3 | Ompetro - Estrutura etária dos trabalhadores pendulares dos fluxos diários, 2010

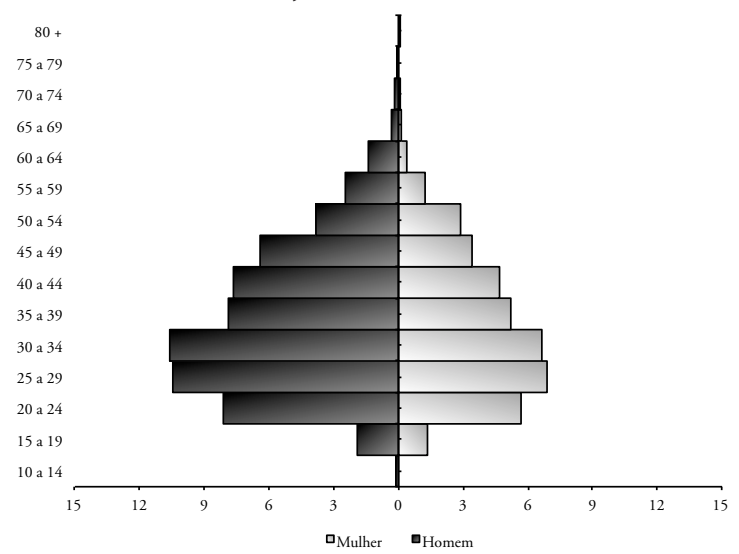

FONTE IBGE - CENSO DEMOGRÁFICO DE 2010

GRÁfICO 4 | Ompetro - Estruturas etárias dos pendulares dos fluxos diários em direção a Armação de Búzios e Macaé, 2010
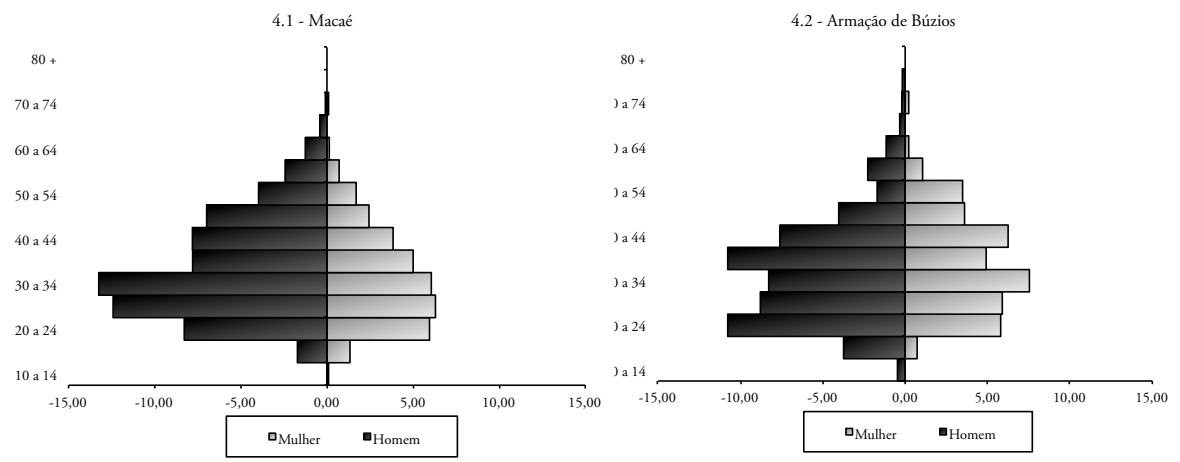

FONTE IBGE - CENSOS DEMOGRÁFICOS DE 2010

Em geral, os pendulares são trabalhadores com baixo nível de escolaridade, mas as distribuiçôes relativas dos pendulares em direção a Armação de Búzios e Macaé, segundo o nível de instrução, revelam haver intensa seletividade na composição desses fluxos, em reflexo a um fenômeno ainda maior, que é o da especialização dos espaços produtivos.

O ápice das distribuições relativas dos pendulares em direção a Armação de Búzios se verifica no primeiro ponto da curva, referente aos indivíduos sem instrução e àqueles que não concluíram o ensino fundamental. Nesse nível de instrução encontravam-se 48,32\% dos indivíduos daquele fluxo, sendo esse percentual mais elevado entre os homens, comparativamente às mulheres. Diferentemente, no fluxo em direção a Macaé, predominam indivíduos com níveis de escolaridade mais elevados: $52,18 \%$ dos indivíduos tinham ensino médio completo ou estavam 
cursando algum curso superior, e 25,03\% dos indivíduos declararam possuir curso superior completo (Gráfico 5).

Embora por meio dessas informaçóes não seja possível estimar as escolaridades médias, pelos diferenciais de níveis e de estrutura das curvas é possível inferir: (1) Macaé atrai indivíduos com nível de escolaridade mais elevado, comparativamente a Búzios; (2) em ambos os fluxos, a escolaridade média é menor entre os homens, embora os diferenciais de escolaridade, segundo o sexo, sejam menos expressivos nos pendulares em direção a Macaé.

\section{GRÁfico 5 | Ompetro - Nível de instrução dos pendulares dos fluxos diários em direção a Armação de Búzios e Macaé, 2010}

FONTE IBGE - CENSO DEMOGRÁFICO DE 20 IO

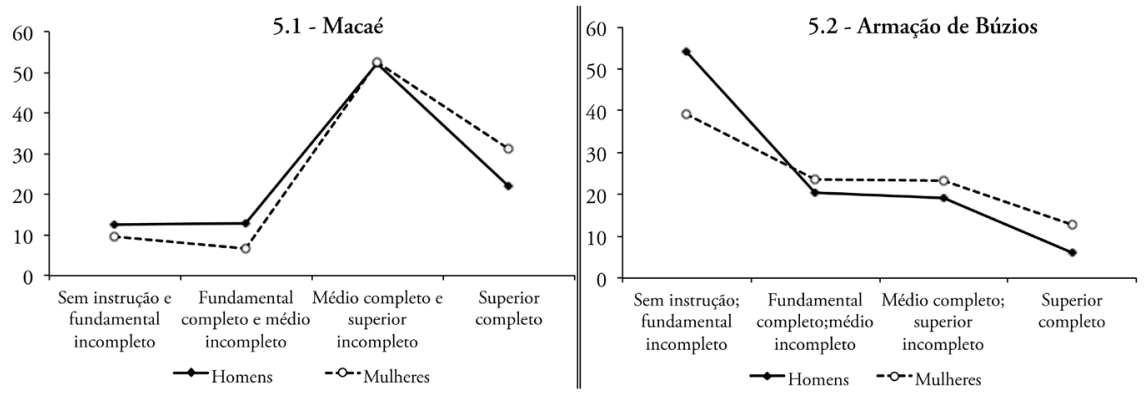

São vários os setores de atividade que absorvem a mão de obra dos pendulares, nos municípios da Ompetro (Quadro 11). No caso específico de Armação de Búzios, há uma notável concentração de trabalhadores pendulares no setor de alojamento e alimentação que, sozinho, absorveu 1.341 trabalhadores (26,42\%). Nesse setor, destacam-se: trabalhadores dos serviços e vendedores dos comércios e mercados; trabalhadores domésticos e de limpeza de interior de edifícios, escritórios, hotéis e outros estabelecimentos; ajudantes na preparação de alimentos; vendedores ambulantes; e trabalhadores de apoio administrativo, tais como trabalhadores de agências de viagens, recepcionistas e telefonistas.

O setor de construção é outro que se destaca pela sua importância na absorção da mão de obra pendular, tendo empregado 1.055 (20,79\%) trabalhadores pendulares, naquele período. Nesse setor, verifica-se um número relativamente alto de profissionais qualificados da construção civil, pintores, limpadores de fachadas, artesãos, trabalhadores qualificados no processamento de alimentos e afins, assim como trabalhadores elementares da construção de obras públicas e da manutenção de estradas, represas e similares, bem como da construção de edifícios. Além desses, são também importantes na absorção dessa mão de obra, os setores de comércio de veículos automotores e motocicletas, e os serviços domésticos (11,37\%).

Em Macaé, o principal setor de absorção da mão de obra pendular é a indústria extrativa mineral, dada a concentraçáo das atividades relacionadas à extração e ao beneficiamento do petróleo. Esse setor emprega relevante número de técnicos e profissionais de nível médio, profissionais das ciências e da engenharia, trabalhadores 
de apoio administrativo e trabalhadores qualificados, operários da construção e das artes mecânicas.

O setor de comércio e reparação de veículos automotores e motocicletas, o segundo mais importante na absorção dos pendulares em Macaé, emprega considerável número de vendedores e de técnicos e profissionais de nível médio, enquanto mais de $50 \%$ dos pendulares absorvidos pelo setor de transporte, armazenagem e correio, o terceiro em destaque, são operadores de instalaçôes e máquinas, e montadores. Merecem destaque, ainda, os setores de atividades administrativas e serviços complementares; a construção civil; administração pública, defesa e seguridade social; e o setor de educação.

QUADro II Ompetro - Rendimento médio e mediano, segundo o setor de atividade, dos trabalhadores pendulares dos fluxos diários em direção a Armação de Búzios e Macaé, 2010

\begin{tabular}{|c|c|c|c|c|c|c|c|c|c|}
\hline \multirow[b]{2}{*}{ GRUPO DE ATIVIDADE } & \multicolumn{3}{|c|}{ ARMAÇÃO DE BÚZIOS } & \multicolumn{3}{|c|}{ MACAÉ } & \multicolumn{3}{|c|}{ OMPETRO } \\
\hline & $(\%)$ & $\begin{array}{l}\text { RENDA } \\
\text { MÉDIA }\end{array}$ & $\begin{array}{c}\text { RENDA } \\
\text { MEDIANA }\end{array}$ & $(\%)$ & $\begin{array}{l}\text { RENDA } \\
\text { MÉDIA }\end{array}$ & $\begin{array}{c}\text { RENDA } \\
\text { MEDIANA }\end{array}$ & $(\%)$ & $\begin{array}{l}\text { RENDA } \\
\text { MÉDIA }\end{array}$ & $\begin{array}{c}\text { RENDA } \\
\text { MEDIANA }\end{array}$ \\
\hline $\begin{array}{l}\text { Agricultura, pecuária, caça } \\
\text { e serviços relacionados }\end{array}$ & 0,51 & 1,2 & 1,0 & 0,05 & 1,4 & 1,4 & 0,40 & 1,9 & 1,0 \\
\hline Indústrias extrativas & - & - & - & 20,23 & 7,6 & 5,9 & 10,82 & 7,4 & 5,3 \\
\hline Indústrias de transformação & 1,93 & 1,4 & 1,3 & 9,00 & 3,8 & 2,4 & 6,66 & 3,4 & 2,0 \\
\hline Eletricidade e gás & - & - & - & 0,88 & 5,9 & 5,3 & 0,58 & 5,2 & 4,9 \\
\hline $\begin{array}{l}\text { Água, esgoto, atividades } \\
\text { de gestão de resíduos e } \\
\text { descontaminação }\end{array}$ & 0,61 & 1,1 & 1,1 & 0,12 & 3,2 & 3,5 & 0,39 & 1,8 & 1,6 \\
\hline Construção & 20,79 & 1,9 & 1,6 & 5,63 & 4,6 & 2,2 & 9,00 & 2,9 & 1,8 \\
\hline $\begin{array}{l}\text { Comércio; reparação de } \\
\text { veículos automotores e } \\
\text { motocicletas }\end{array}$ & 12,87 & 1,8 & 1,4 & 10,76 & 2,9 & 1,9 & 12,65 & 2,3 & 1,6 \\
\hline $\begin{array}{l}\text { Transporte, armazenagem } \\
\text { e correio }\end{array}$ & 0,89 & 1,5 & 1,6 & 7,77 & 3,6 & 2,8 & 6,27 & 3,1 & 2,4 \\
\hline Alojamento e alimentação & 26,42 & 1,5 & 1,3 & 3,00 & 2,2 & 1,7 & 6,87 & 1,8 & 1,4 \\
\hline Informação e comunicação & 0,43 & 0,7 & 1,0 & 2,77 & 4,5 & 2,4 & 2,01 & 3,7 & 2,0 \\
\hline $\begin{array}{l}\text { Atividades financeiras, } \\
\text { de seguros e serviços } \\
\text { relacionados }\end{array}$ & 0,75 & 1,6 & 1,1 & 1,31 & 5,8 & 5,5 & 1,36 & 4,6 & 3,9 \\
\hline Atividades imobiliárias & 0,45 & 11,0 & 15,7 & 0,44 & 3,4 & 3,9 & 0,57 & 6,1 & 3,9 \\
\hline $\begin{array}{l}\text { Atividades profissionais, } \\
\text { científicas e técnicas }\end{array}$ & 1,00 & 3,2 & 3,9 & 3,57 & 4,5 & 3,1 & 2,87 & 5,4 & 3,1 \\
\hline $\begin{array}{l}\text { Atividades administrativas } \\
\text { e serviços complementares }\end{array}$ & 5,38 & 1,5 & 1,4 & 5,73 & 1,7 & 1,4 & 5,00 & 1,6 & 1,4 \\
\hline $\begin{array}{l}\text { Administração pública, } \\
\text { defesa e seguridade social }\end{array}$ & 4,99 & 3,9 & 2,8 & 4,94 & 4,7 & 3,5 & 8,57 & 3,8 & 2,8 \\
\hline Educação & 3,98 & 2,6 & 2,9 & 5,20 & 3,8 & 2,9 & 6,92 & 3,0 & 2,4 \\
\hline $\begin{array}{l}\text { Saúde humana e serviços } \\
\text { sociais }\end{array}$ & 1,85 & 2,7 & 1,6 & 2,55 & 3,7 & 2,4 & 3,78 & 3,5 & 2,0 \\
\hline $\begin{array}{l}\text { Artes, cultura, esporte e } \\
\text { recreação }\end{array}$ & 0,79 & 2,4 & 1,8 & 0,24 & 7,3 & 7,8 & 0,56 & 3,4 & 2,2 \\
\hline
\end{tabular}


(continuação)

\begin{tabular}{|c|c|c|c|c|c|c|c|c|c|}
\hline \multirow[b]{2}{*}{ GRUPO DE ATIVIDADE } & \multicolumn{3}{|c|}{ ARMAÇÃO DE BÚZIOS } & \multicolumn{3}{|c|}{ MACAÉ } & \multicolumn{3}{|c|}{ OMPETRO } \\
\hline & $(\%)$ & $\begin{array}{l}\text { RENDA } \\
\text { MÉDIA }\end{array}$ & $\begin{array}{c}\text { RENDA } \\
\text { MEDIANA }\end{array}$ & $(\%)$ & $\begin{array}{l}\text { RENDA } \\
\text { MÉDIA }\end{array}$ & $\begin{array}{c}\text { RENDA } \\
\text { MEDIANA }\end{array}$ & $(\%)$ & $\begin{array}{l}\text { RENDA } \\
\text { MÉDIA } \\
\end{array}$ & $\begin{array}{c}\text { RENDA } \\
\text { MEDIANA }\end{array}$ \\
\hline $\begin{array}{l}\text { Outras atividades de } \\
\text { serviços }\end{array}$ & 1,18 & 1,2 & 1,0 & 0,61 & 2,1 & 1,6 & 1,04 & 1,8 & 1,6 \\
\hline Serviços domésticos & 11,37 & 1,1 & 1,0 & 2,33 & 1,2 & 1,0 & 4,97 & 1,1 & 1,0 \\
\hline $\begin{array}{l}\text { Organismos internacio- } \\
\text { nais e outras instituições } \\
\text { extraterritoriais }\end{array}$ & - & - & - & - & - & - & - & - & - \\
\hline Atividades mal definidas & 3,80 & 1,5 & 1,4 & 12,86 & 4,7 & 3,7 & 8,70 & 4,1 & 2,9 \\
\hline Total & 5.103 & 1,8 & 1,4 & 16.217 & 4,5 & 2,9 & 31.609 & 3,5 & 2,0 \\
\hline
\end{tabular}

FONTE IBGE - CENSO DEMOGRÁFICO DE 2010

$\mathrm{Na}$ Quadro 11 encontram-se, igualmente, as rendas médias e medianas dos fluxos pendulares no interior da Ompetro, segundo o setor de atividade, com destaque para aqueles em direção a Búzios e Macaé. A renda média dos trabalhadores pendulares dos municípios da Ompetro era de 3,5 salários mínimos, sendo que 50\% dos pendulares tinham um rendimento mensal na ocupação principal de, no máximo, 2 SM. Mais uma vez, as diferenças entre os fluxos em direção a Búzios e Macaé são perceptíveis: os pendulares que trabalham em Búzios têm um rendimento médio e mediano inferior àqueles dos pendulares absorvidos pelo mercado de trabalho macaense, em praticamente todos os setores de atividade, com exceção das "atividades imobiliárias". Em Búzios, os pendulares inseridos nas "atividades imobiliárias" -menos de 0,5\%- tinham um rendimento médio mensal de 11 SM. Depois desse setor, destaca-se a "administração pública, defesa e seguridade social", com um rendimento médio de 3,9 SM, e o setor de "atividades profissionais, científicas e técnicas”, com renda média de 3,2 SM. Em Macaé, os trabalhadores pendulares mais bem remunerados são os empregados na "indústria extrativa" (7,6 SM), no setor de "artes, cultura, esporte e recreaçáo" (7,3 SM), no setor de "eletricidade e gás" (5,9 SM) e nas "atividades financeiras, seguros e serviços relacionados" (5,8 SM). Com exceção da "indústria extrativa", os outros setores que se destacam, pelo nível relativamente alto do rendimento médio de seus trabalhadores são pouco significativos como absorvedores da mão de obra pendular.

\section{Consideraçóes finais}

Os municípios pertencentes à Ompetro vêm passando por intensas mudanças demográficas e socioeconômicas decorrentes dos crescentes investimentos -diretos e indiretos- relacionados à atividade petrolífera e parapetrolífera.

Em relação à dinâmica demográfica, nos chama a atenção a elevação do ritmo de crescimento populacional e sua maior participação relativa no incremento absoluto estadual, o aumento dos poderes de atração e retenção populacional desses municípios, além da maior concentração da população nesta região.

Observou-se um incremento, entre 2000 e 2010, do número de indivíduos que trabalham em município diferente do município de residência. Entre os pendulares prevalecem, nos dois períodos, aqueles que trabalham em outro município do 
próprio Estado do Rio de Janeiro: 14,11\% do total de trabalhadores remunerados e $98,34 \%$ dos trabalhadores pendulares de 2000 ; e $16,68 \%$ do total e $94,66 \%$ dos pendulares de 2010.

Considerando-se apenas os municípios pertencentes à Ompetro, o aumento da pendularidade é também expressivo: de 14.019 trabalhadores, em 2000, para 43.642, em 2010. Nos dois períodos, apenas Macaé e Búzios apresentaram saldos pendulares positivos, indicando que esses municípios mais recebem do que perdem trabalhadores para outros municípios da própria Ompetro. São mercados de trabalho capazes de absorver grande parte da mão de obra residente, e também grande parte da mão de obra residente em outros municípios.

Entre os pendulares de 2010, 31.611 indivíduos retornam para casa diariamente. Nesses fluxos predominam homens, sobretudo mais jovens, mas há uma diferença significativa entre os fluxos em direção a Búzios e Macaé. Além das diferenças absolutas -o fluxo em direção a Macaé é aproximadamente 6 vezes maior do que aquele em direção a Búzios- a proporção de homens no fluxo para Macaé é maior, comparativamente a Búzios. Isso porque a maior atratividade do mercado de trabalho daquele município é exercida pelo setor industrial, principalmente a indústria extrativa, enquanto nesse, o destaque é para o setor de turismo que, pela natureza de suas atividades, absorve com maior facilidade a mão de obra feminina.

Em geral, os pendulares são trabalhadores mais pobres, que apresentam baixo nível de escolaridade e rendimento. Ressalta-se também que, nesse aspecto, há diferenças significativas entre os fluxos de Búzios e Macaé. Assim é que, em direção a Macaé, tem-se um pendular de "maior qualidade" (maior escolaridade e rendimento médio) comparativamente a Armação de Búzios.

Em suma, esses resultados comprovam o recrudescimento da mobilidade pendular no interior da Ompetro, indicam um aumento da interaçáo demográfica e socioeconômica, e refletem as disparidades socioeconômicas existentes entre esses municípios, assim como a concentração espacial da atividade produtiva. Além do mais, esses resultados indicam, ainda, o "plus populacional que deve ser considerado na formulação de políticas públicas de atendimento desta parcela da população no município de trabalho [...] e, em contrapartida, a formulação de políticas de geração de emprego no município de origem" (Jardim, Barcellos, 2004 apud Moura, Castello Branco e Firkowski, 2005, p. 129).

\section{Referências bibliográficas}

Antico, C. (2005). Deslocamentos pendulares na Região Metropolitana de São Paulo. São Paulo em Perspectiva, 19(4), 110-120. http://dx.doi.org/10.1590/S010288392005000400007

Aranha, V. (2005). Mobilidade pendular na metrópole paulista. São Paulo em Perspectiva, 19(4), 96-109. http://dx.doi.org/10.1590/S0102-88392005000400006 
Baeninger, R. (2000). Migraçôes internas no Brasil: Municípios metropolitanos e não metropolitanos. Anais do ii Encontro Nacional sobre Migraçáo (pp. 535-562). Belo Horizonte: Associação Brasileira de Estudos Populacionais (ABEP).

Baeninger, R. (2003). Cidades e Metrópoles: a desaceleração no crescimento populacional e novos arranjos regionais. Anais do xi Congresso Brasileiro de Sociologia. Campinas, São Paulo: Associação Brasileira de Estudos Populacionais (ABEP). Em http//www. sbsociologia.com.br/portal/index.php?option=com

Baeninger, R. (2004). Interiorização da migraçáo em Sáo Paulo: novas territorialidades e novos desafios teóricos. Anais do xiv Encontro Nacional de Estudos Populacionais (pp. 1-14) Caxambu: Associaçáo Brasileira de Estudos Populacionais (ABEP).

Baeninger, R. \& Ojima, R. (2008). Novas territorialidades e a sociedade de risco: evidências empíricas e desafios teóricos para a compreensão dos novos espaços da migração. Papeles de Población. Nueva Época, 14(58), 141-154. Em http://www.redalyc.org/ articulo.oa?id $=11205808$

Brito, F. \& Souza, J. (2005). Expansão urbana nas grandes metrópoles: o significado das migraçóes intrametropolitanas e da mobilidade pendular na reprodução da pobreza. São Paulo em Perspectiva, 19(4), 48-63. http://dx.doi.org/10.1590/S010288392005000400003

Carvalho, A. M. \& Silva, E. T. (2006). Dinâmica demográfica no norte fluminense. Em A. M. Carvalho \& M. E. F. Totti (Orgs.), Formação histórica e econômica do Norte Fluminense (pp. 131-168). Rio de Janeiro: Garamond.

Cunha, J. M. P. (1995). Migração intrametropolitana: movimento dos pobres? Revista Brasileira de Estudos de População, 12(1/2), 59-80.

Fernandes, J. S., Terra, D. C. T. \& Campos, M. M. (2012). O migrante na reestruturação do mercado de trabalho na zona da produção principal da Bacia de Campos. Apresentação de Pôsters. xviii Encontro Nacional de Estudos Populacionais 2012, Transformaçōes na População Brasileira: complexidades, incertezas e perspectiva, realizado em Águas de Lindóia, Sáo Paulo, de 19 a 23 de novembro 2012. Em http://www.abep.nepo. unicamp.br/xviii/anais/files/POSTER[653]ABEP2012.pdf

Germani, G. (1974). Sociologia da modernização: estudos teóricos, metodológicos e aplicados a América Latina. São Paulo: Mestre Jou.

Instituto Brasileiro de Geografia e Estatística (IBGE). (2010). Censo 2010. Em http://censo2010. ibge.gov.br/es/

Lee, E. S. (1980). Uma teoria sobre a migração. In H. A. Moura (Org.), Migração interna, textos selecionados (pp. 89-114). Fortaleza: Banco do Nordeste do Brasil/Escritório Técnico de Estudos Econômicos do Nordeste (вNв/Entene). (Versão original, 1966).

Martine, G. (1980). Adaptaçâo dos migrantes ou sobrevivência dos mais fortes? In H. A. Moura (Org.), Migração interna, textos selecionados (pp. 949-974). Fortaleza: Banco do Nordeste do Brasil/Escritório Técnico de Estudos Econômicos do Nordeste (BNB/Entene).

Matos, R. (2000). Aglomeraçóes urbanas, redes de cidades e desconcentração demográfica no Brasil. XII Encontro Nacional de Estudos Populacionais (pp. 1-22). Caxambu, Minas Gerais: Associação Brasileira de Estudos Populacionais (ABEP). Em http://www.abep. nepo.unicamp.br/docs/anais/pdf/2000/Todos/migt4_3.pdf 
Matos, R. \& Ferreira, R. N. (2008). Dinamismo do mercado de trabalho formal e mobilidade espacial de trabalhadores. Anais do xvi Encontro Nacional de Estudos Populacionais. Caxambú, Minas Gerais: Associaçáo Brasileira de Estudos Populacionais (ABEP). Em http://www.abep.nepo.unicamp.br/encontro2008/docsPDF/ABEP2008 -1147.pdf

Mincer, J. (1978). Family Migration Decisions. The Journal of Political Economy, 86(5), 749773. doi: $10.1086 / 260710$.

Monié, F. (2003). Petróleo, industrialização e organização do espaço regional. In R. Piquet (Org.), Petróleo, royalties e região. Rio de Janeiro: Garamond.

Moura, R., Castello Branco, M. L. G. \& Firkowski, O. L. C. F. (2005). Movimento pendular e perspectivas de pesquisas em aglomerados urbanos. São Paulo em Perspectiva, 19(4), 121-133. http://dx.doi.org/10.1590/S0102-88392005000400008

Pereira, R. H. M. \& Herrero, V. (2009). Mobilidade pendular: Uma proposta teóricometodológica. Texto para discussão $n^{\circ}$ 1395. Rio de Janeiro: Instituto de Pesquisa Econômica Aplicada (IPEA). Em http://www.ipea.gov.br/portal/images/stories/PDFs/ TDs/td_1395.pdf

Pinho, B. A. T. D. de. (2012). Mobilidade pendular e mercado de trabalho na Regiäo Metropolitana de Belo Horizonte: uma análise a partir dos dados dos Censos Demográficos. Dissertação de Mestrado. Centro de Desenvolvimento e Planejamento Regional da Faculdade de Ciências Econômicas (FACE/UfMG).

Piquet, R. (2003). Da cana ao petróleo: Uma região em mudança. In R. Piquet (Org.), Petróleo, royalties e região (pp. 219-238). Rio de Janeiro: Garamond.

Ravenstein, E. G. (1980). As leis das migraçôes. In H. A. Moura (Org.), Migração interna, textos selecionados (pp. 25-88). Fortaleza: Banco do Nordeste do Brasil/Escritório Técnico de Estudos Econômicos do Nordeste (BNB/Entene). (Versão original, 1885).

Redwood III, J. (1984). Reversión de polarización, ciudades secundarias y eficiencia en el desarrollo nacional: una visión teórica aplicada al Brasil contemporáneo. EURE, 11(32). 35-56. Em http://www.eure.cl/index.php/eure/article/view/948/60

Silva, E. T. (2011). Censo 2010: As metrópoles na dinâmica demográfica. Boletim Semanal [Observatório das Metrópoles, Instituto Nacional de Ciência e Tecnologia] n ${ }^{\circ}$ 174, de 32/02/2011. Em: http://www.observatoriodasmetropoles.net/download/metropoles_ censo.pdf

Singer, P. (1980). Migraçôes internas: consideraçôes teóricas sobre o seu estado. In H. A. Moura (Org.), Migração interna, textos selecionados (pp. 211-244). Fortaleza: Banco do Nordeste do Brasil/Escritório Técnico de Estudos Econômicos do Nordeste (BNB/ Entene). (Versão original, 1976).

Sjaastad, L. A. (1980). Os custos e o retorno da migração. In H. A. Moura (Org.), Migração interna, textos selecionados (pp. 115-144). Fortaleza: Banco do Nordeste do Brasil/ Escritório Técnico de Estudos Econômicos do Nordeste (BNB/Entene). (Versão original, 1885).

Souza, J. (2008). Expansão urbana de Belo Horizonte e da Região Metropolitana de Belo Horizonte: $O$ Caso específico do município de Ribeirão das Neves. Tese de Doutorado defendida no Departamento de Demografia da Faculdade de Ciências Econômicas da Universidade Federal de Minas Gerais (Cedeplar/face/ufmG) em 27 de Fevereiro de 2008. 
Souza, R. G. V. \& Brito, F. (2006). A expansão urbana da região metropolitana de Belo Horizonte e suas implicaçóes para a redistribuição espacial da população: a migração dos ricos. XV Encontro de Estudos Populacionais, Associação Brasileira de Estudos Populacionais (abep), realizado em Caxambu, Minas Gerais, de 18 a 22 de setembro de 2006. Em http://trinnityconsultoria.com.br/efacil/arquivos/pdf/arquivo_10.pdf

Stamm, C. \& Staduto, J. A. R. (2008). Movimentos pendulares das cidades interioranas de porte médio de Cascavel e Toledo, no Paraná. Revista Brasileira de Estudos de População, 25(1), 131-149. Em http://www.scielo.br/pdf/rbepop/v25n1/v25n1a08

Todaro, M. P. (1980). A migração da mão-de-obra e o desemprego urbano em países subdesenvolvidos. In H. A. Moura (Org.), Migração interna, textos selecionados (pp. 145-172). Fortaleza: Banco do Nordeste do Brasil/Escritório Técnico de Estudos Econômicos do Nordeste (вNB/Entene). (Versão original, 1969). 